\title{
Hydrological Property Measurements of Topopah Spring Tuff
}

\author{
Jeffery J. Roberts \\ Wunan Lin
}

Manuscript Date: October 1994

Publication Date: April 1995

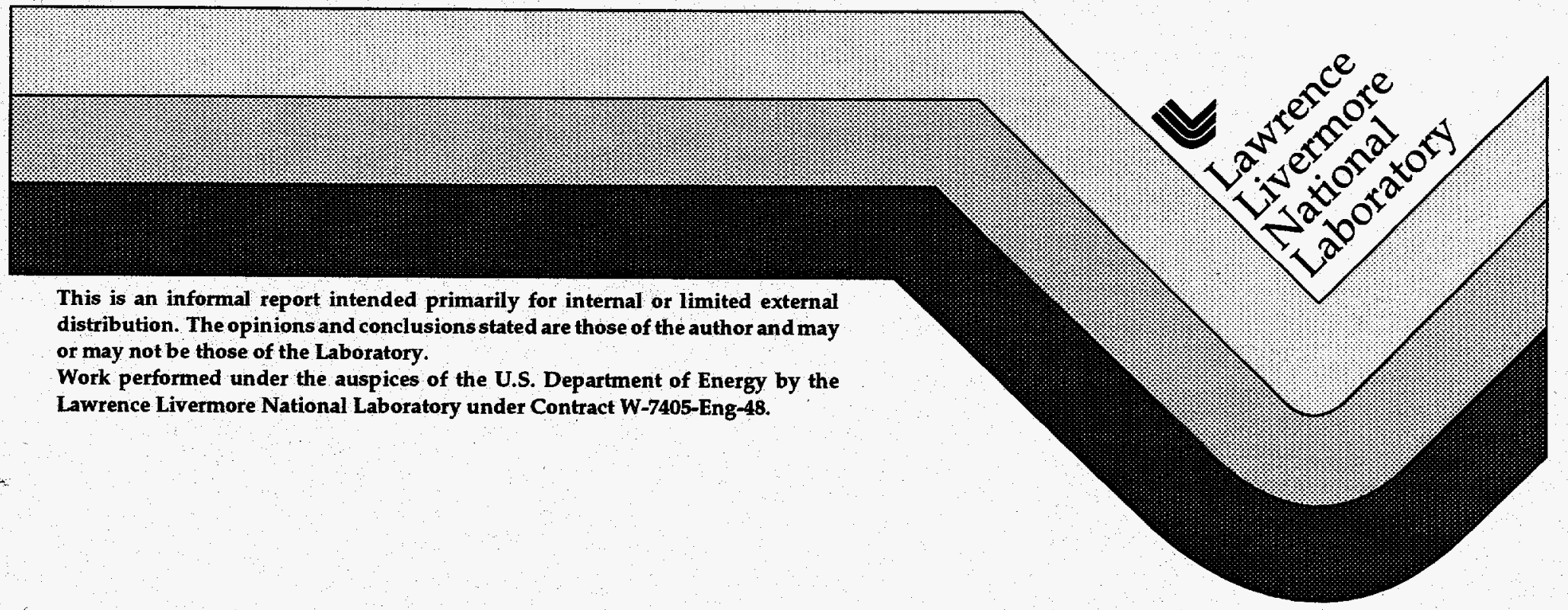




\section{DISCLAIMER}

This document was prepared as an account of work sponsored by an agency of the United States Government. Neither the United States Government nor the University of California nor any of their employees, makes any warranty, express or implied, or assumes any legal liability or responsibility for the accuracy, completeness, or usefulness of any information, apparatus, product, or process disclosed, or represents that its use would not infringe privately owned rights. Reference herein to any specific commercial product, process, or service by trade name, trademark, manufacturer, or otherwise, does not necessarily constitute or imply its endorsement, recommendation, or favoring by the United States Government or the University of California. The views and opinions of authors expressed herein do not necessarily state or reflect those of the United States Government or the University of California, and shall not be used for advertising or product endorsement purposes.

This report has been reproduced directly from the best available copy.

Available to DOE and DOE contractors from the Office of Scientific and Technical Information P.O. Box 62, Oak Ridge, TN 37831

Prices available from (615) 576-8401, FTS 626-8401

Available to the public from the

National Technical Information Service

U.S. Department of Commerce

5285 Port Royal Rd,

Springfield, VA 22161 


\section{DISCLAIMER}

Portions of this document may be illegible in electronic image products. Images are produced from the best available original document. 
Milestone Report MOL80

\title{
Hydrological Property Measurements of Topopah Spring Tuff
}

\author{
Introduction
}

This report documents the progress made during FY 1994 on hydrological property measurements of samples from Topopah Spring tuff at Yucca Mountain, Nevada. These measurements were performed in the laboratory at Lawrence Livermore National Laboratory. This report contains descriptions of experimental designs and procedures, data, observations, and preliminary analyses, and also describes planned future work. The report is organized into three sections:

1. Permeability of fractured Topopah Spring tuff as a function of temperature and confining pressure

2. Electrical properties of Topopah Spring tuff as a function of temperature and of saturation

3. Moisture retention measurements of Topopah Spring tuff as a function of temperature.

\section{Permeability as a Function of Temperature and Confining Pressure}

Understanding hydrologic transport in the subsurface is critical to predicting and modeling the hydrothermal performance of a geologic nuclear waste repository. The host rock of the potential nuclear waste repository at Yucca Mountain, Nevada, is Topopah Spring tuff. Previous permeability measurements of intact tuff rocks from Yucca Mountain indicate low permeability values-on the order of a microdarcy $(\mu \mathrm{D})$-that are insensitive to temperature (Lin and Daily, 1984).

Because of the fractured nature of Topopah Spring tuff, the effective permeability of the rock/fracture system is much higher. Previous measurements of permeability of a single fracture in tuff indicate permeabilities on the order of hundreds of millidarcies (mD) (Daily et al., 1987). As suggested by Lin and Daily (1989), fracture permeability may change as a function of time with the passage of high temperature water through the fracture. It is possible that "fracture healing" will lower the permeability of a rock/fracture system by one or more orders of magnitude. This report updates our progress on laboratory experiments designed to investigate and quantify the lowering of permeability as a function of confining pressure, temperature, and amount of fluid passed through samples of Topopah Spring tuff that contain only a single fracture. 


\section{Sample Description and Preparation}

A suitable sample containing a single open fracture was located in a 6-cm-diameter core obtained from borehole USW-G4, sample ID number 17351.1. The sample selected was taken from the depth interval 342.23 to $342.29 \mathrm{~m}$. The fracture was not visibly mineralized or altered. The sample was subcored to a diameter of $5.085 \mathrm{~cm}$ and a final length of $6.335 \mathrm{~cm}$. The sample was carefully machined and no additional visible fractures were created during this process. The porosity of the sample was calculated by subtracting the dry density from the saturated density and dividing by the water density. The porosity was determined to be $10.3 \%$.

\section{Experimental Design and Procedure}

Figure 1 is a schematic of the general experimental design. The sample was jacketed with a water-impermeable Viton jacket and fitted with Hastalloy end caps. Hastalloy end caps were used because of their resistance to corrosion and to prevent $\mathrm{Fe}$ from entering the fluid/rock system. The sample was placed in a pressure vessel that was heated externally by use of a standard resistance heater. Two thermocouples (type J) were placed at either end of the sample outside the Viton jacket. The temperature $(T)$ at either end of the sample was constant to within $\pm 2^{\circ} \mathrm{C}$ at room temperature and $\pm 5^{\circ} \mathrm{C}$ at the highest temperature of $-160^{\circ} \mathrm{C}$. Confining pressure was maintained through the use of a Haskel pump controlled with an air-actuated Annin valve using Dow Corning $200 \mathrm{Si}$ fluid as the pressurizing medium. A separator with a series of metering and shut-off valves controlled the upstream and downstream pressures $\left(\mathrm{P}_{\mathrm{up}}\right.$, $\left.P_{\mathrm{dn}}\right)$. A differential pressure transducer measured the pressure difference $(\Delta \mathrm{P})$ across the sample length. The $\Delta P$ was measured accurately to within $\pm 0.1 \%$. Prior to a permeability measurement, the background differential pressure was measured during a period of zero flow. This background pressure was subtracted from the $\Delta P$ reading in the permeability calculation (vide infra). Pore water pressure ( $\mathrm{P}_{\text {pore }}$ ) was kept at $\sim 4.8$ to 5.8 bars throughout the experiment by a separator in which nitrogen gas pressure was maintained by a regulator and relief valve. The permeability was found to be independent of pore pressure over this range.

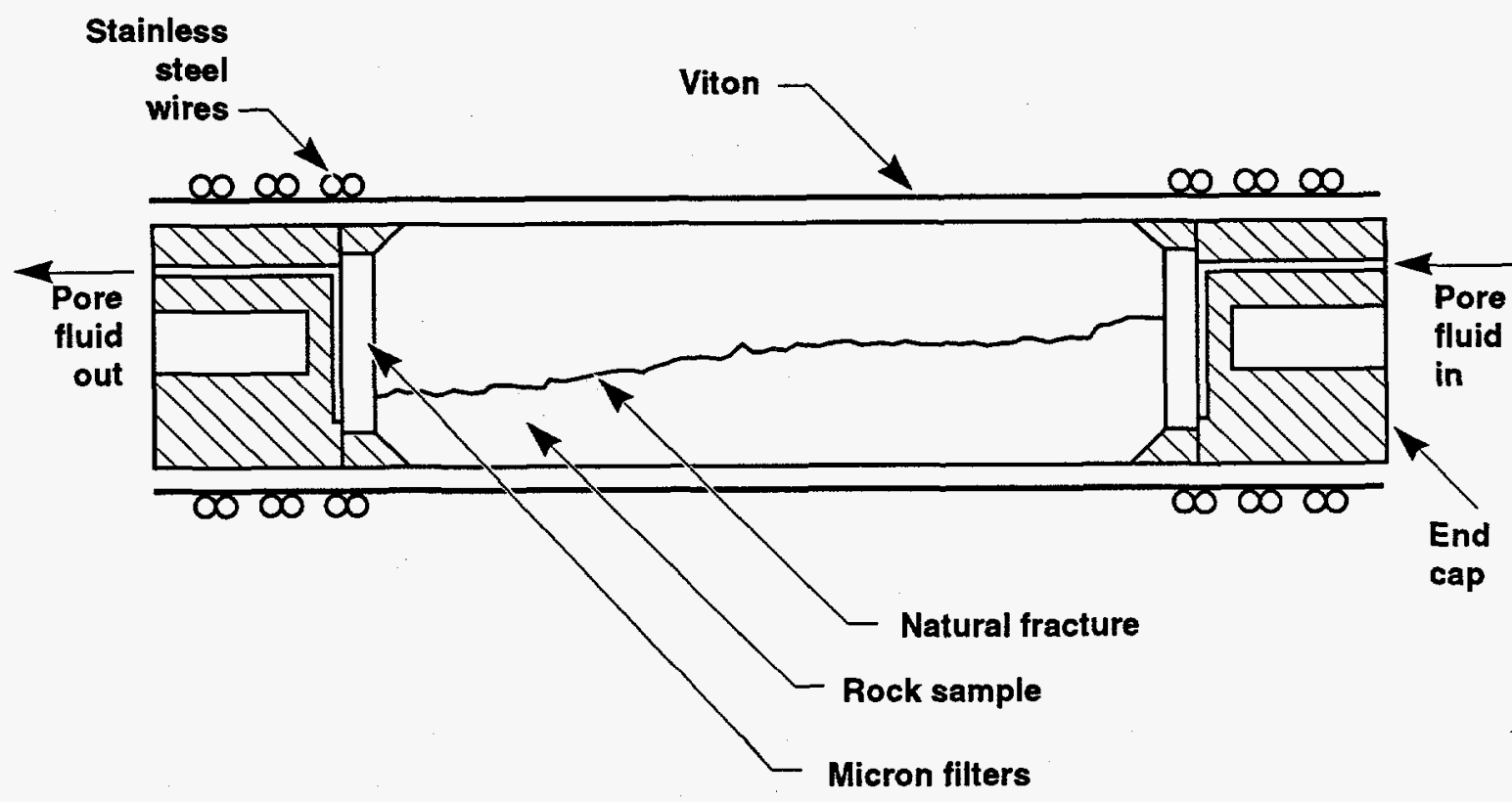

Fig. 1. Schematic of the Sample and Jacketing System.

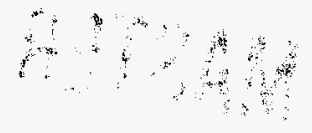


The saturating fluid used within the sample is water from well J-13 doped with $1 \mathrm{~g} / \mathrm{L}$ sodium azide as an inhibitor to bacterial growth. Water was sampled after each experimental run and chemically analyzed using inductively-coupled plasma atomic emission spectrometry. The analyses included a check for leakage of confining fluid (Si oil) through the Viton jacket. No leaks were detected. Periodic inspections of fluid passing through the sample using scanning electron microscopy were performed to check for bacterial growth. No bacterial growth that could affect the permeability measurements was observed.

At a specified set of conditions $\left(P_{c}, \Delta P\right.$, and $T$ ), the flow rate was measured by observing the water column in a burette and timing the flow with a stopwatch. All parameters were either recorded with a computer, recorded in a scientific notebook, or both. The total amount of water that flowed through the sample was carefully tracked and recorded. Four permeability measurements were made at each $\Delta \mathrm{P}$, and measurements were made at 3 or 4 different $\Delta P$ s for each set of conditions. It was found that the permeability varied linearly over the range $0.1 \leq \Delta \mathrm{P} \leq 0.4$ bars (Fig. 2). The permeabilities reported here correspond to $\Delta \mathrm{P}=0.2$ bar.

\section{Permeability Calculation}

The equation that describes permeability is Darcy's equation. For water flow along the sample axis,

$$
k=\mu Q l / A \Delta \mathrm{P},
$$

where $k$ is the permeability, $\mu$ is the viscosity of water, $Q$ is the flow rate, $A$ is the area of the sample, and $l$ is the sample length. The viscosity of water at each temperature was obtained from Eisenberg and Kauzmann (1969). Permeability was converted from $\mathrm{m}^{2}$ units to the standard unit of permeability, the darcy (D), where $1 \mathrm{D}=10^{-12} \mathrm{~m}^{2}$. The error in the permeability measurement depends on a number of

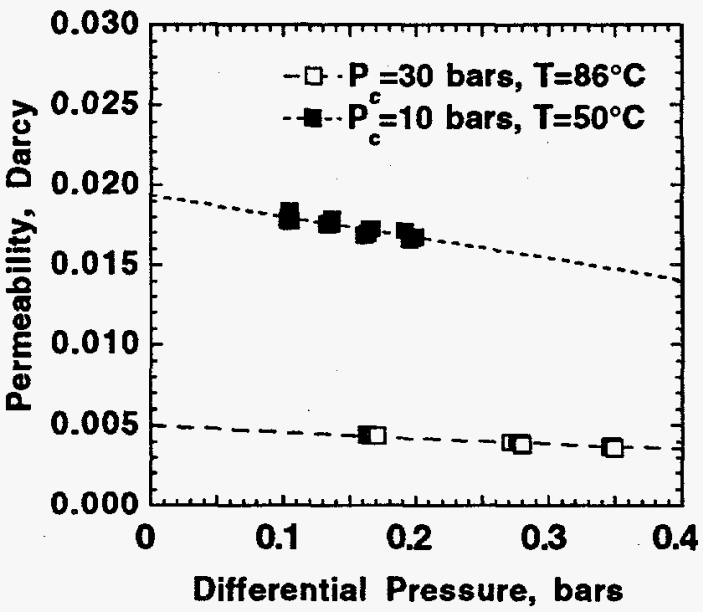

Fig. 2. Permeability vs. $\Delta P$ in Topopah Spring tuff with a single fracture for two different experiments, one with $P_{c}=10$ bars at $50^{\circ} \mathrm{C}$, and another with $P_{c}$ $=30$ bars at $86^{\circ} \mathrm{C}$. Permeability is a linear function of differential pressure over this range of pressures.

factors, and through the propagation of errors (e.g., Bevington and Robinson, 1992), the error for Eq. 1 is estimated to be less than 3\%.

\section{Experimental Results}

A general overview of the first 4200 hours of the experiment is shown in Fig. 3(a), which shows permeability and temperature $(T)$ as functions of time, and in Fig. 3(b), which shows permeability and $P_{c}$ as functions of time. In Fig. 3 (a), error bars were calculated for permeability but, in general, they are smaller than the size of the data symbols. During the first portion of the experiment, the temperature was held constant at room temperature, and $\mathrm{P}_{\mathrm{c}}$ was increased stepwise to 50 bars and then decreased to the starting point of 10 bars. Clearly, the permeability decreased with increasing $P_{c}$ and recovered to near the starting value of $\sim 18 \mathrm{mD}$ upon returning to $P_{c}=10$ bars. This indicates that confining pressure alone might not irreversibly affect the permeability.

Next, temperature was increased to $\sim 155^{\circ} \mathrm{C}$, and then decreased to room temperature $\left(23^{\circ} \mathrm{C}\right)$, while $\mathrm{P}_{\mathrm{c}}$ was kept at 10 bars. This resulted in a decrease in permeability from 



Fig. 3. (a) Permeability of single-fracture Topopah Spring tuff (USW G4) and T( ${ }^{\circ} \mathrm{C}$ ) as functions of elapsed experiment time. Each temperature cycle results in a decrease in permeability of about $50 \%$. Note the slight recovery in permeability following rapid cooling at 2900 and $\mathbf{4 2 0 0}$ hours. (b) Permeability and $P_{c}$ as functions of elapsed time. Note the inverse relationship between confining pressure and permeability during the early part of this experiment.

$\sim 18$ to $8 \mathrm{mD}$. A period of steam flow was generated at $\sim 1700$ hours by lowering the pore pressure to below that of the steam point. This had little effect on the permeability of the fractured sample. Permeability measurements were attempted during steam flow but were not successful due to difficulty in maintaining steady differential pressures.

Next, the $P_{c}$ was increased to 20 bars and another temperature excursion was performed. The result was a further lowering in the permeability to $\sim 4 \mathrm{mD}$. Steam was again flowed through the sample, and had little effect on the permeability. The last part of the experiment was to increase the $P_{c}$ to 30 bars and cycle through temperature once more. There was only a small change in the permeability during this cycle. The lowest permeability value reached during any portion of the experiment was $\sim 3.2 \mathrm{mD}$ at around 4000 hours. An interesting observation is the increase in permeability at approximately 2900 and 4050 hours. These small increases occurred following the cooling portion of the temperature cycles for $\mathrm{P}_{\mathrm{c}}=20$ and $\mathrm{P}_{\mathrm{c}}=30$ bars. One possibility is that the cooling was rapid enough to create thermal gradient fracturing, temporarily increasing the permeability, and these fractures then subsequently healed or closed.

\section{Chemical Analysis of Pore Fluid}

Pore fluid was collected as the experiment progressed. Care was taken to collect samples corresponding to the conditions under which they were tested. That is, a sample collected at a certain set of conditions $\left(T, P_{c}\right)$, flowed through the rock under those same conditions. The water samples were chemically analyzed using inductively-coupled plasma atomic emission spectrometry for $\mathrm{K}, \mathrm{Na}, \mathrm{Ca}, \mathrm{B}, \mathrm{Si}$, $\mathrm{Al}$, and $\mathrm{Fe}$. No $\mathrm{Fe}$ or $\mathrm{Al}$ was detected above the detectability limits of 0.02 and $0.06 \mathrm{~g} / \mathrm{mL}$, respectively. The chemical analyses are complete only up to the $\sim 3350$ th hour of the experiment. Future analyses will include fluoride, chloride, and sulfate concentrations.

It is instructive to plot the chemical analyses and permeabilities as functions of $T$ and $P_{c}$ and examine these plots to identify trends. This has been done in Figs. 4 and 5. Two 
samples of water or pore fluid were collected and analyzed during each sample collection period, and data from both are plotted in these figures; therefore the analysis at any one time may have two different values. Typical accuracies are $\pm 2 \%$. Figures 4 (a) through 4(e) are plots of temperature and the aqueous concentration of $\mathrm{K}$, i.e., [K], and of [Na], [Ca], [B], and [Si] as functions of elapsed time of the experiment. Similarly, Figs. 5(a) through 5(e) are plots of $\mathrm{P}_{\mathrm{c}}$ and $[\mathrm{K}],[\mathrm{Na}],[\mathrm{Ca}],[\mathrm{B}]$, and [Si] as functions of elapsed time of the experiment.
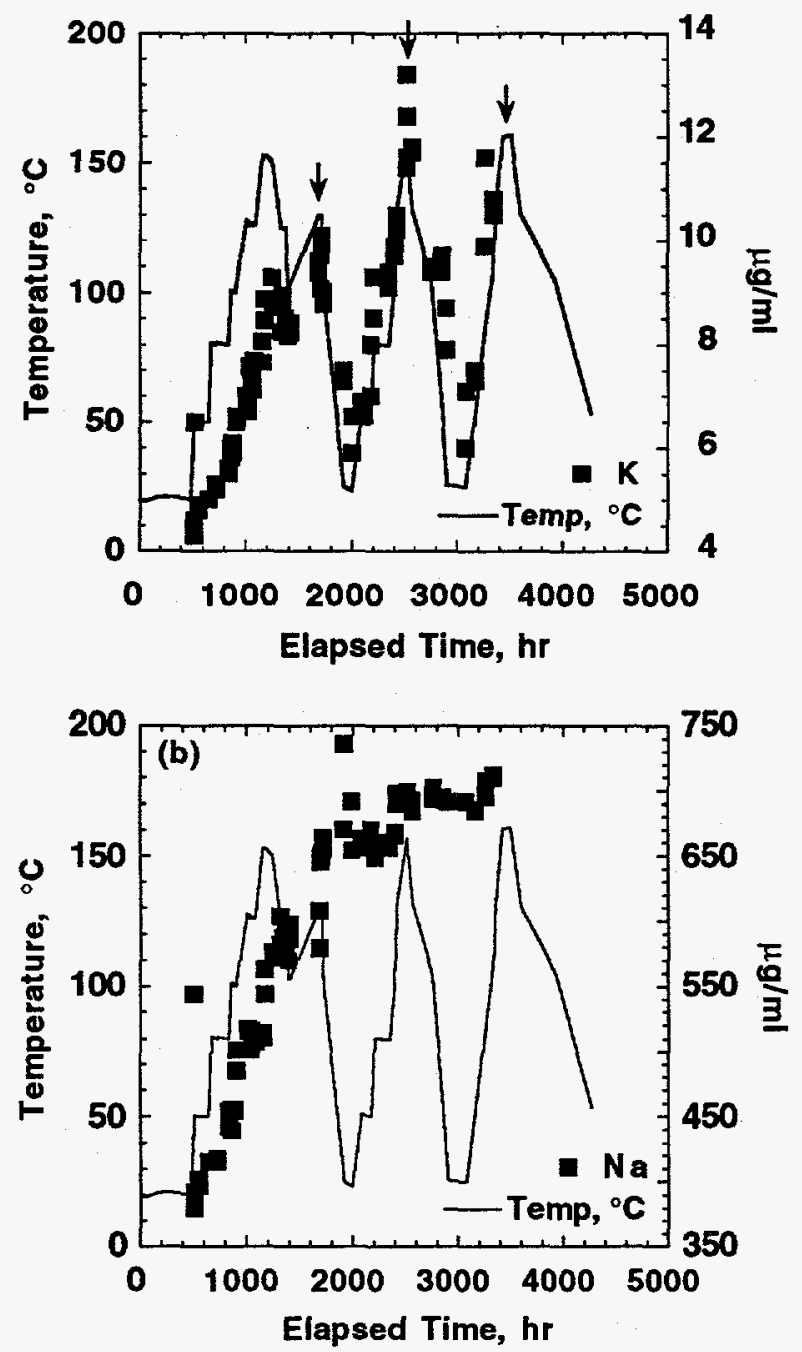
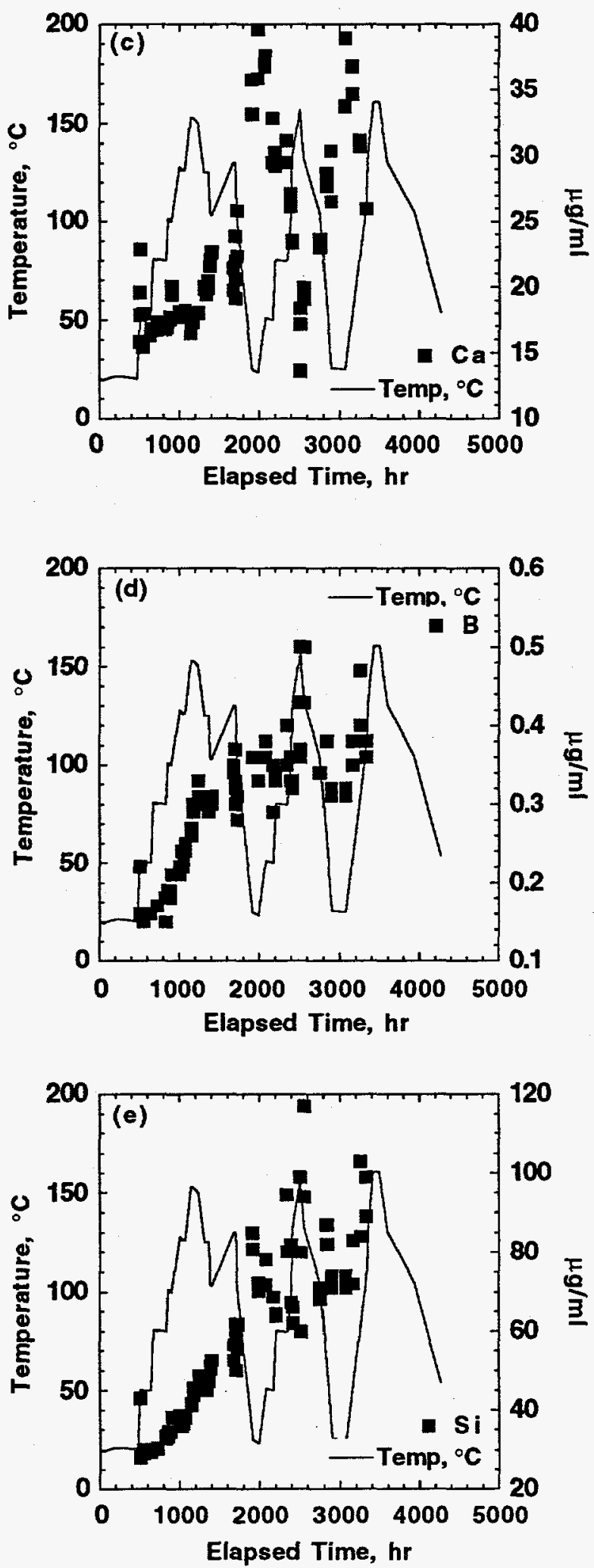

Fig. 4. Temperature $\left({ }^{\circ} \mathrm{C}\right)$ and chemical concentration $(\mu \mathrm{g} / \mathrm{mL})$ as functions of elapsed time for (a) [K], where arrows indicate periods of steam flow, (b) [Na], (c) [Ca], (d) [B], and (e) [Si]. For ease of viewing, the temperature is plotted as a line. 


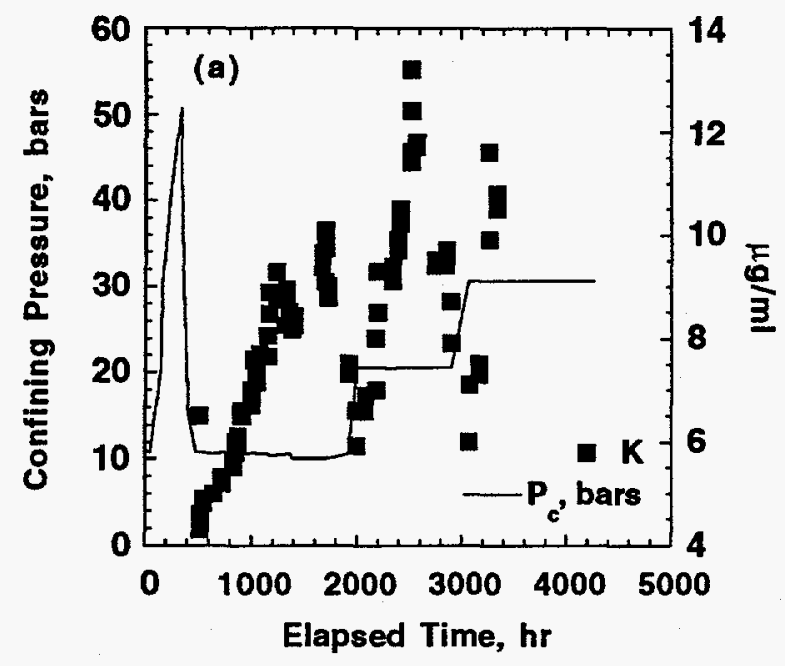

Note that potassium concentration [K] strongly correlates with temperature [Fig. 4(a)], but not with pressure [Fig.5(a)]. $\mathrm{Na}$ concentration is artificially high because of the sodium azide, but increases with $\mathrm{P}_{\mathbf{c}}$ [Fig. 5(b)]. This also indicates that [Na] increases with decreasing permeability. [Ca] displays an inverse temperature correlation [Fig. 4(c)]. Boron seems to correlate with temperature [Fig. 4(d)]. Silicon generally increases as time (and cumulative water) increases, and displays a weak correlation with temperature [Fig. 4(e)]. The $\mathrm{pH}$ of the
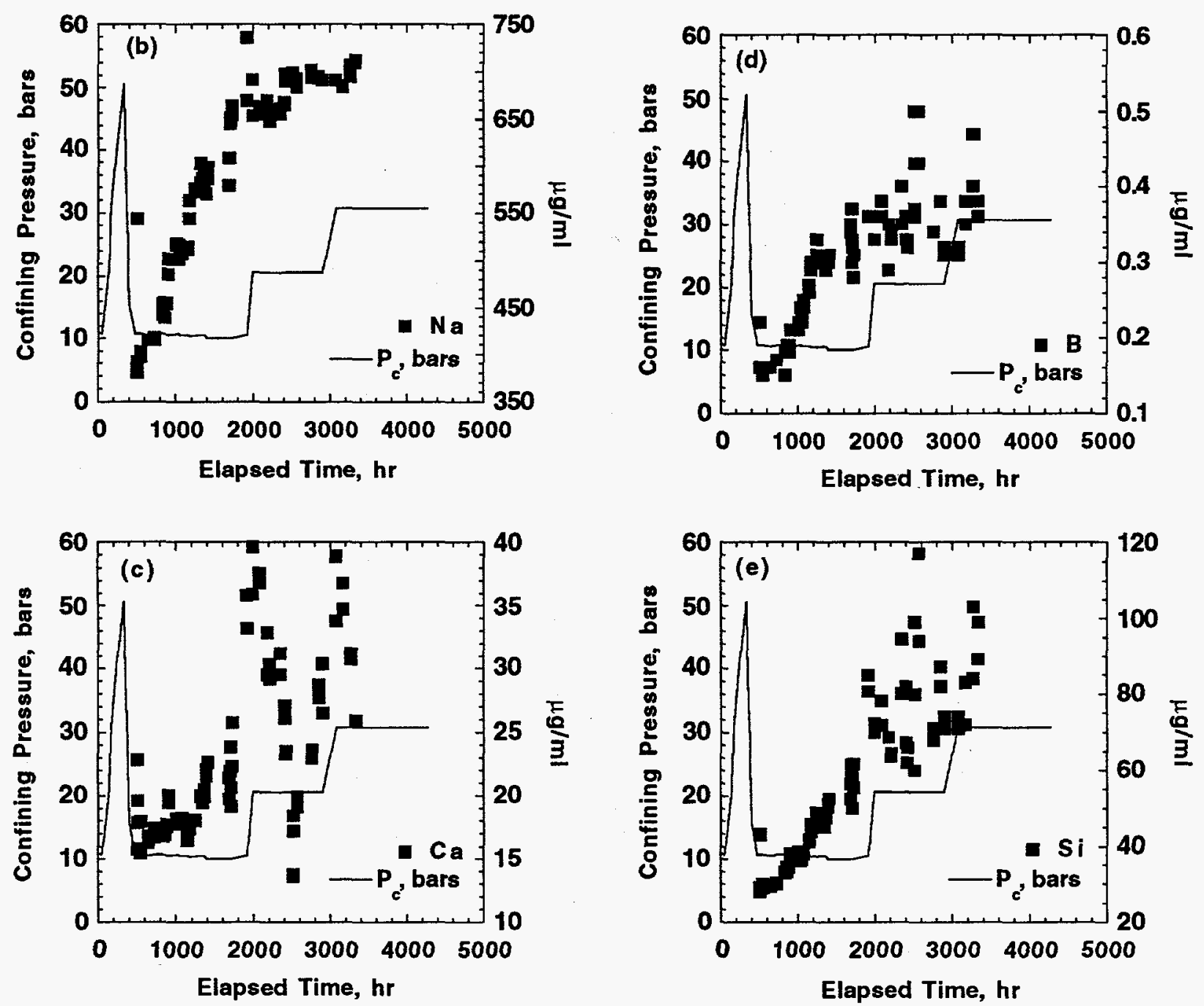

Fig. 5. $P_{c}$ and chemical concentration $(\mu \mathrm{g} / \mathrm{mL})$ as functions of elapsed time (hours) for (a) $[\mathrm{K}]$, (b) $[\mathrm{Na}]$, (c) [Ca], (d) [B], and (e) [Si]. For ease of viewing, the confining pressure is plotted as a line. 
fluid was also measured and was found to vary between 7.9 and 8.7. No systematic variation with time, $T$, or $P_{c}$ is apparent. These results are preliminary and will be analyzed in more detail in the future.

\section{Effect of Steam Flow}

Steam flow was created by lowering pore pressure to below that of the steam point and maintaining a differential pressure. Steam flow was created in the sample at approximately 1705,2519 , and 3428 hours of elapsed time, and $26.7,23.0$, and $6.0 \mathrm{~mL}$ of liquid water was flowed as steam at 130,156 , and $156^{\circ} \mathrm{C}$ (respectively). The steam flow had no obvious effect on permeability; however, it may have affected the chemistry of the pore fluid. Water samples were collected before and after steam flow and analyzed at each sample collection period. In the two analyses obtained thus far, $\mathrm{Si}, \mathrm{K}, \mathrm{Ca}$, and $\mathrm{B}$ concentrations decreased by 6 to $32 \%$ after steam flow. In general, the decrease in elemental concentration appears to be greater at $P_{c}=20$ bars as compared to $P_{c}=10$ bars. For example, during the first steam flow period, [Si] decreased from 61.4 and $59.4 \mu \mathrm{g} / \mathrm{mL}$ to 57.8 and $50.0 \mu \mathrm{g} / \mathrm{mL}$. During the second steam flow period ( $2519 \mathrm{hrs})$, [Si] decreased from 99 and $80 \mu \mathrm{g} / \mathrm{mL}$ to 60 and $60 \mu \mathrm{g} / \mathrm{mL}$. This is a potentially important feature of steam flow that could affect silica redistribution and possibly the fracture healing process. We will look for this phenomenon in future experiments. In the first determination $(\sim 1705 \mathrm{hr})$, the $\mathrm{pH}$ increased slightly. No increase in $\mathrm{pH}$ was observed for the second steam flow period.

\section{Conclusion}

It is important to note that changes in permeability during this study are not strictly a result of any one parameter change (e.g., $T, P_{c}$, or water/rock ratio) but are caused by some or all of these in a complex manner. Thus, the history of the sample is important. In any case, these experiments are conducted in such a way as to study the changes in permeability in a systematic manner. The results will be examined in the framework of existing models with regard to fracture aperture and geochemistry.

These experiments are ongoing. Future experiments will isolate, to the extent possible, the separate effects of confining pressure changes, temperature excursions, and steam flow. 


\section{Electrical Properties as Functions of Temperature and Saturation}

The electrical properties of partially saturated tuff are important because the determination of water saturation during field tests and laboratory experiments depends on reliable laboratory data. These measurements also provide information about the microstructure of the matrix and how water is distributed within the pore space as the material undergoes saturation and desaturation cycles. A description of the experimental procedure, sample preparation, data collection, and data analyses for three different tuff samples follows.

\section{Experimental Procedure}

A paper presented at the 1994 International High Level Radioactive Waste Management Conference (Roberts and Lin, 1994) contains the results of much of our work and a detailed description of our experimental procedure. For convenience, this paper is included in this report as Appendix 1. Our subsequent work is described below.

Measurements were made at room temperature $\left(23^{\circ} \mathrm{C}\right), 40^{\circ} \mathrm{C}$, and $65^{\circ} \mathrm{C}$, and additional measurements at $95^{\circ} \mathrm{C}$ are in progress. The range of saturation $\left(S_{\mathrm{w}}\right)$ varied from 0 to near $100 \%$. Briefly, electrical resistivity and dielectric permittivity were measured as a function of frequency $\left(10^{-3}\right.$ to $\left.10^{5} \mathrm{~Hz}\right)$. Measurements were made over a range of frequency to verify measurements made at a single frequency and to provide additional information about conduction mechanisms and microstructural parameters. Resistivity measurements are reported for one frequency, $1 \mathrm{kHz}$, as this frequency was determined to be free of electrode contamination (contact impedance) and represents the electrical properties of the material. Dielectric permittivity measurements are reported at $100 \mathrm{kHz}$, the highest frequency used. Several samples of different thickness of each rock were prepared and measured under the same conditions to verify that measurements were not affected by electrode properties or fringing of the electrical field, and as a measure of sample heterogeneity.

Water from well J-13 was added in small amounts to a dry sample and allowed to distribute throughout the sample. This typically required 3 to 4 hours as verified by examining the resistivity of a sample as a function of time. Saturations were determined by weighing the samples immediately after electrical measurements were completed. Each sample was placed in a custom-built holder made of Lucite and separated from the atmosphere by an O-ring seal. Despite these precautions, water was lost from samples when measurements at relatively high $S_{w}$ were attempted at 40 and $65^{\circ} \mathrm{C}$. The holders were placed in a standard oven at 40 or $65^{\circ} \mathrm{C}$ and allowed time to equilibrate to the temperature (typically overnight). Temperature was measured at 3 points inside the oven using type-J thermocouples placed in aluminum blocks. The temperatures were the same at each point to within $\pm 3^{\circ} \mathrm{C}$ (and usually within $\pm 1.5^{\circ} \mathrm{C}$ ). The maximum $S_{W}$ achieved decreased as the temperature of measurement increased (from approximately $87 \%$ at $40^{\circ} \mathrm{C}$ to $78 \%$ at $65^{\circ} \mathrm{C}$ ). Upon reaching maximum saturation, the drying portion of the measurements began. During the drying phase, samples were air dried or dried in an oven at $35^{\circ} \mathrm{C}$. Some sample damage in the form of chipping and cracking occurred because of the cooling and heating that was necessary when a sample was taken out of the oven, removed from its holder, weighed, saturated/dried, and placed back in its holder and into the temperaturecontrolled oven. Samples were no longer used 
when the measurement of electrical properties became unreliable. Duplicate samples of each rock type prevented this breakage from stopping the measurements.

Samples were prepared from cores obtained from boreholes USW GU-3 (GU3) at $330 \mathrm{~m}$ depth (Area 25, TSw2), USW G-4 (G4) at $374 \mathrm{~m}$ depth (Area 25, TSw2), and U3hg-1 (U3hg) at $399 \mathrm{~m}$ depth (Area 3). The samples from GU3 and G4 are of particular importance because they are the same rock as at the potential repository horizon. Measurements at 40 and $65^{\circ} \mathrm{C}$ were performed only on the samples from GU3 and G4. As described in Appendix 1, samples were machined in two different orientations: parallel and perpendicular to the layering (fabric). The samples are disk-shaped, with a diameter of approximately $5.1 \mathrm{~cm}$ and a diameter-to-thickness aspect ratio of $\geq 10: 1$ (dime-shaped). Throughout this report, samples with layering parallel to the direction of measurement (current flow) are referred to as transverse samples because they are machined perpendicular to the core axis. They are identified by the suffix - $T$ in the figures. All other samples were prepared with thelayered direction perpendicular to the direction of measurement.

\section{Resistivity and Dielectric Permittivity as Functions of Saturation and Temperature}

The electrical resistivity and dielectric permittivity of $\mathrm{G} 4$ at 23,40 , and $65^{\circ} \mathrm{C}$ as a function of $S_{W}$ are plotted in Figs. 6(a) and (b). Both the wetting and drying curves are shown for $23^{\circ} \mathrm{C}$. Only the wetting curves are shown at 40 and $65^{\circ} \mathrm{C}$. The highest saturation levels achieved are lower for the higher temperature experiments. A small amount of hysteresis is observed; however, there appears to be no marked increase in resistivity during the wetting phase, unlike previous measurements utilizing distilled water as the saturating fluid (Appendix 1). When hysteresis is observed, the wetting curve is less resistive and
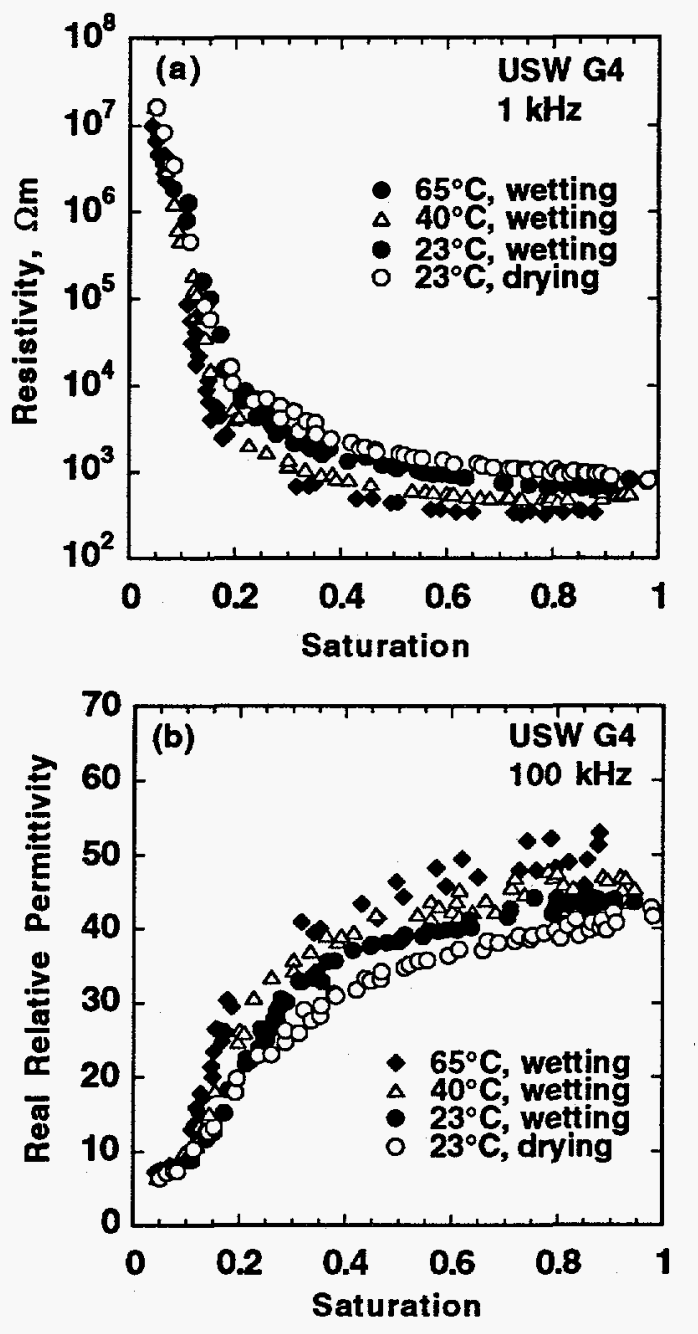

Fig. 6. (a) Electrical resistivity and (b) relative permittivity vs. $S_{w}$ for USW G4 as functions of $T$. Resistivities reported were measured at $1 \mathrm{kHz}$ and relative permittivities at $100 \mathrm{kHz}$.

has a higher relative permittivity than the drying curve. The cause of the increase in resistivity when distilled water is the saturating fluid has not yet been explained.

The resistivity decreases as temperature increases over the range of saturation from approximately 15 to $90 \%$. The resistivity varies from $>10^{7} \Omega \mathrm{m}$ at $0 \% \mathrm{~S}_{\mathrm{W}}$ to $<10^{3} \Omega \mathrm{m}$ at the highest saturations achieved. Considering only the wetting portions of the curves, the resistivity decreases about half an order of magnitude when temperature is increased from 23 to $65^{\circ} \mathrm{C}$. At lower saturations ( $<10$ to 
$15 \% \mathrm{~S}_{\mathrm{w}}$ ), the curves are insensitive to temperature. This is interpreted as an indication that the adsorption of water and surface conduction dominate this region of saturation. Above these saturation levels, the variability of fluid electrical properties with temperature appears to play a role in the bulk electrical properties. The manner in which the water wets the sample, and how this distribution of water affects the electrical properties, is currently under investigation.

The dielectric permittivity plotted in Fig. 6(b) displays features similar to those seen in the resistivity vs. saturation plots. At low saturations, the curves are insensitive to temperature and a small amount of hysteresis is observed. The dielectric permittivity increases with increasing temperature and saturation. The values at $0 \% \mathrm{~S}_{\mathrm{w}}$ are $\sim 5$ and at the highest saturations range from $\sim 40$ to 60 . For comparison, the dielectric permittivity of pure water is $\sim 78$ at room temperature. The amount of scatter in the data increases as temperature is increased. One possible explanation is that the susceptibility of capacitance measurements to noise at the highest frequencies of measurement $(100 \mathrm{kHz})$ is greater at higher temperatures.

Resistivity vs. saturation curves for the GU3 samples are shown in Figs. 7(a) and (b) for both wetting and drying at 40 and $65^{\circ} \mathrm{C}$. Figures 8(a) and (b) show the dielectric permittivity vs. $S_{W}$ for both wetting and drying at 40 and $65^{\circ} \mathrm{C}$. Figure 9 displays the wetting curve of dielectric permittivity as a function of temperature. These data display similar features to those discussed above for G4. The main points are the low hysteresis between wetting and drying and the different shape of the dielectric permittivity vs. saturation curves. These differences can probably be explained by microstructural and textural differences between the two materials (see Table 1, Appendix 1). The dielectric permittivity increases significantly with increasing temperature (Fig. 9).
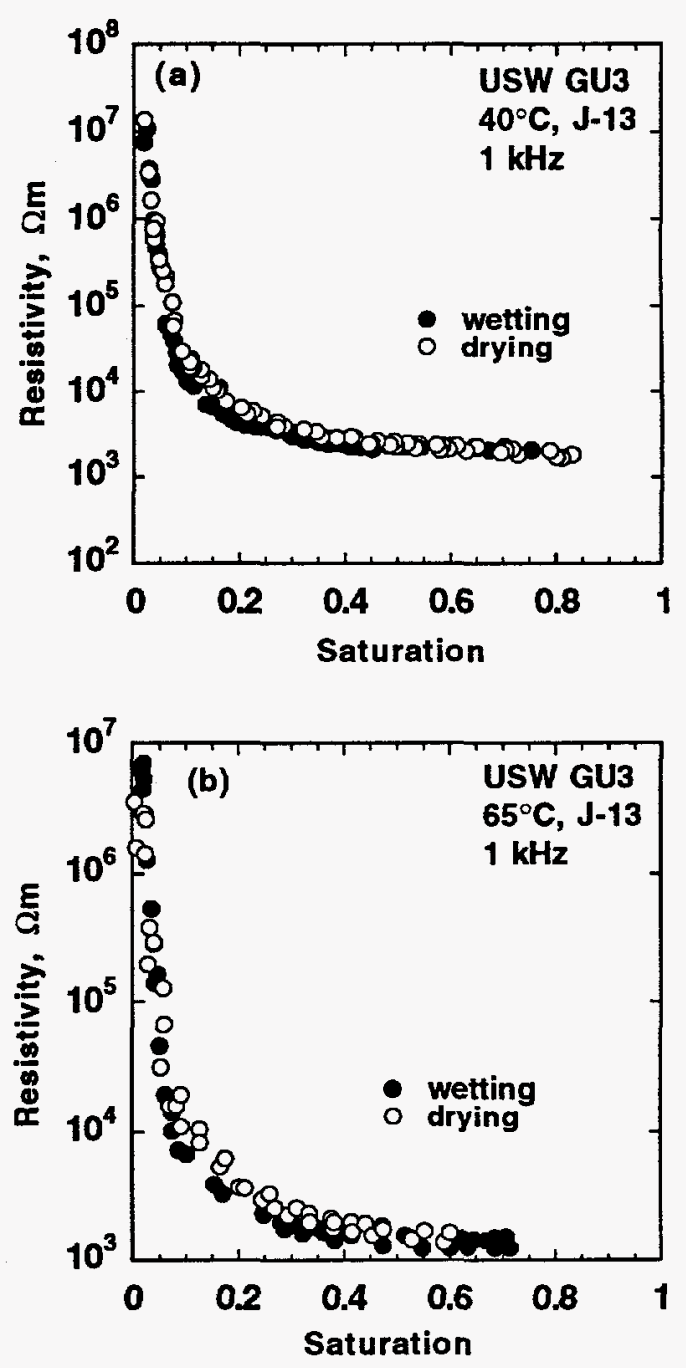

Fig. 7. Electrical resistivity vs. saturation for USW GU3 at (a) $40^{\circ} \mathrm{C}$ and (b) $65^{\circ} \mathrm{C}$. Very little hysteresis was observed between wetting and drying for this rock at these conditions.

\section{Measurements of Electrical Anisotropy}

Measurements were performed to examine possible anisotropy, with respect to the layering of the rock, in the densely welded tuff samples. The results are plotted in Figs. 10(a) and (b) and Figs. 11(a) and (b). As described previously, when the direction of current flow is parallel to the layering of the rock, the curve is identified with the suffix, $-T$. The samples taken perpendicular to the layering of the rock have no special designation. A small amount 

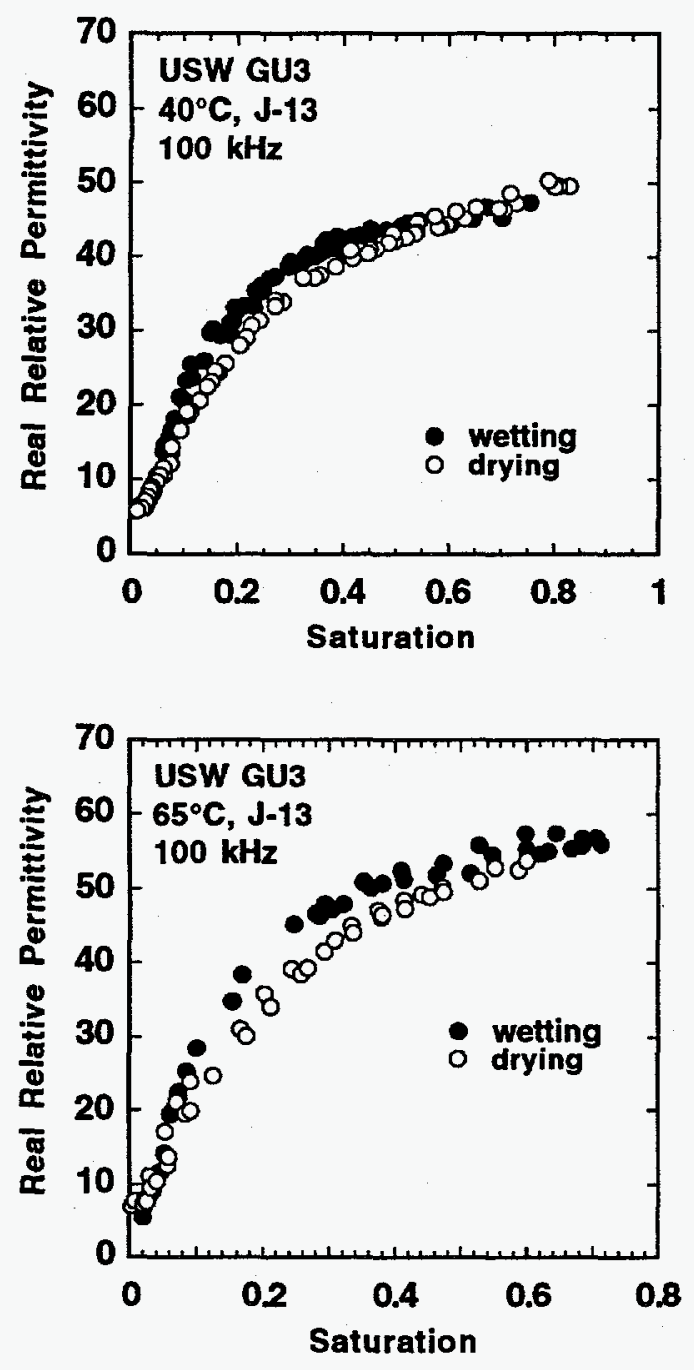

Fig. 8. Relative permittivity $\left(\kappa^{\prime}\right)$ vs. saturation for USW GU3 at (a) $40^{\circ} \mathrm{C}$ and (b) $65^{\circ} \mathrm{C}$. Hysteresis is more pronounced in $\mathrm{K}^{\prime}$ than in resistivity.

of anisotropy was observed, with the axis of the borehole (vertical direction, perpendicular to layering) less conductive than the direction perpendicular to the borehole axis (horizontal direction, parallel to layering, $-\mathrm{T}$ ).

Resistivities reported were measured at $1 \mathrm{kHz}$, and relative permittivities were measured at $100 \mathrm{kHz}$. The GU3 tuff exhibits a greater degree of anisotropy than does G4. The total porosity of GU3 is also higher than that of $\mathrm{G} 4$ by approximately $0.3 \%$ (Table 1 , Appendix 1).

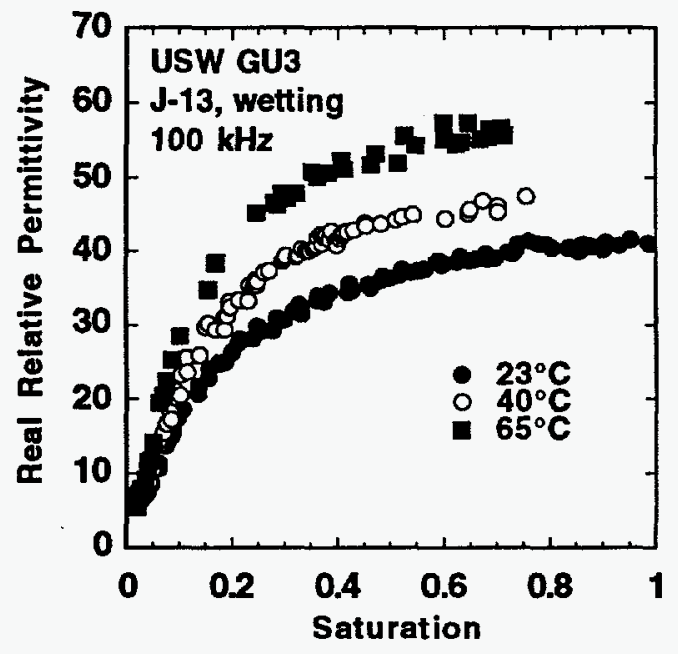

Fig. 9. Relative permittivity $\left(\kappa^{\prime}\right)$ vs. saturation for USW GU3 at 23,40 , and $65^{\circ} \mathrm{C}$. The $K^{\prime}$ increases as T increases. At the lowest $S_{w}(<0.1)$, the measurement is insensitive to temperature.

\section{Future Work on Electrical Properties}

Measurements at $95^{\circ} \mathrm{C}$ are in progress. Additional samples are being machined to replace chipped and cracked samples. Measurements performed at $95^{\circ} \mathrm{C}$ on the newer samples that have not previously been subjected to repetitive saturation/desaturation cycles and heating/cooling cycles at 40 and $65^{\circ} \mathrm{C}$ will help determine the importance of sample history for these measurements, and quantify how these cycles change the surface properties of the tuff.

The results will be analyzed in terms of existing mixing-model theory. Water distribution and wetting behavior as a function of saturation will be studied further. We will attempt to identify the conduction mechanisms at low saturation and relate them to surface properties (internal pore surfaces) such as cation exchange capacity. We will also perform in-depth analyses of the frequencydependent electrical properties. 



Fig. 10. (a) Electrical resistivity and (b) relative permittivity vs. saturation for USW G4 as a function of direction of measurement. Filled symbols represent measurements made in the 'normal' direction, open circles represent measurements made in the transverse direction (-T). The direction of measurement has little effect on the electrical properties of USW G4 at these conditions.
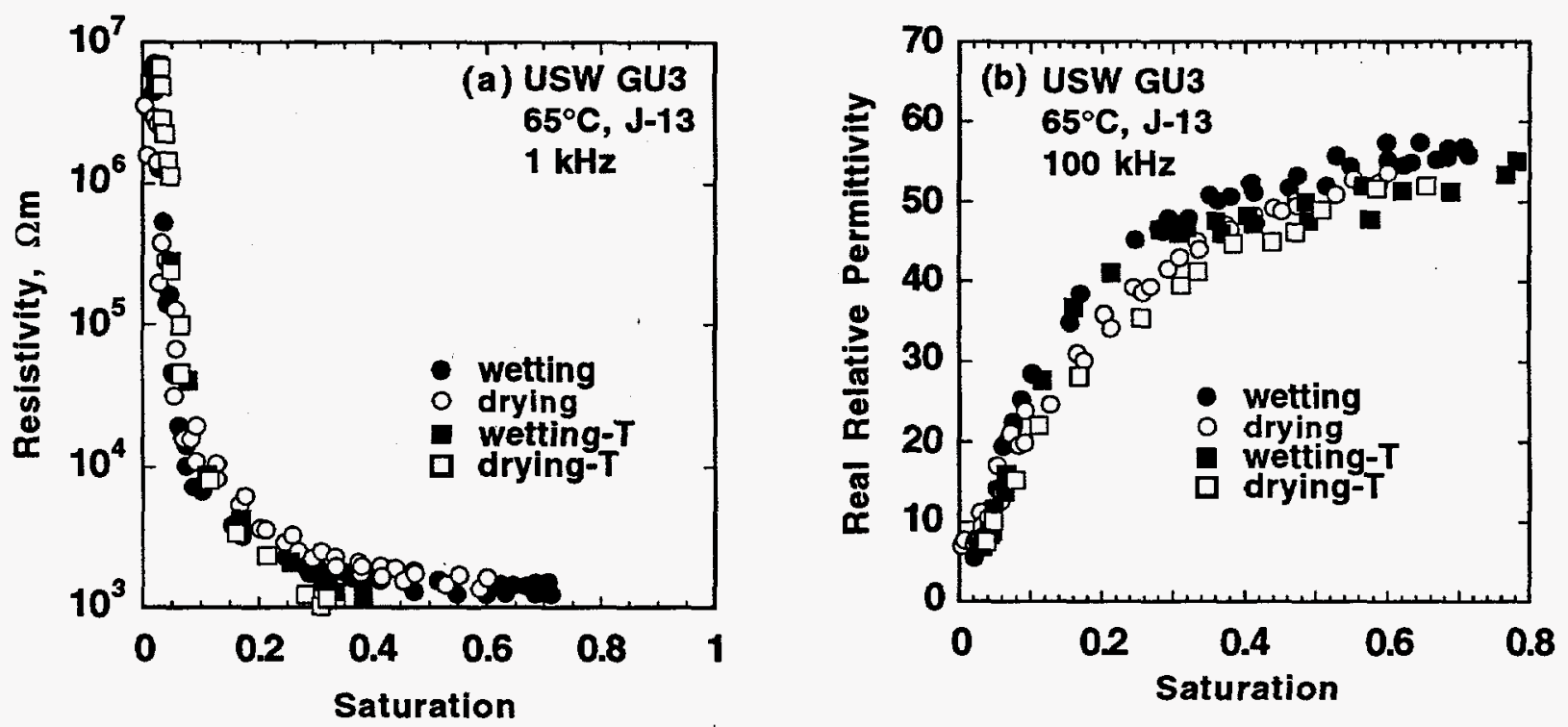

Fig. 11. (a) Electrical resistivity and (b) relative permittivity vs. saturation for USW GU3 as a function of direction of measurement. Above $\sim 25 \% S_{w}$, both resistivity and relative permittivity are lower for the transverse direction. 


\section{Moisture Retention Measurements as Functions of Temperature}

Knowledge of unsaturated transport properties is essential for understanding the movement and migration of water through the unsaturated zone. Evaluation of the performance of a potential nuclear waste repository also depends on these properties. Moisture retention data are important input for models of fracture-flow matrix imbibition interactions in tuff. We have begun the measurement of moisture retention on tuff from 25 to $95^{\circ} \mathrm{C}$ that will provide data needed for this purpose.

\section{Sample Description and Preparation}

Twelve samples were prepared from borehole USW-G4, sample ID 17350.3, $349.6 \mathrm{~m}$ depth. The samples were subcored to a diameter of $19.1 \mathrm{~mm}$ and cut into disks approximately $2.5 \mathrm{~mm}$ thick. Samples with obvious large cavities and inhomogeneous inclusions were avoided. The average porosity of the 12 samples is $11.1 \pm 1.7 \%$, determined by subtracting the dry density from the saturated density and dividing by the water density (see Table 1).

Table 1. Porosity of Samples (ID 17350.3) for Moisture Retention Measurements.

\begin{tabular}{clll}
\hline \multirow{2}{*}{ Sample \# } & \multicolumn{2}{c}{ Density $\left(\mathrm{g} / \mathrm{cm}^{3}\right)$} & \\
\hline \hline 1 & Dry & Wet & Porosity \\
\hline 2 & 2.30 & 2.39 & 0.093 \\
3 & 2.28 & 2.38 & 0.103 \\
4 & 2.30 & 2.40 & 0.099 \\
5 & 2.29 & 2.39 & 0.101 \\
6 & 2.26 & 2.36 & 0.102 \\
7 & 2.20 & 2.33 & 0.127 \\
8 & 2.18 & 2.32 & 0.137 \\
9 & 2.26 & 2.37 & 0.108 \\
10 & 2.27 & 2.37 & 0.099 \\
11 & 2.18 & 2.32 & 0.145 \\
12 & 2.23 & 2.35 & 0.121 \\
Average & 2.31 & 2.40 & 0.095 \\
& $2.25 \pm 0.05$ & $2.37 \pm 0.03$ & $0.111 \pm 0.017$ \\
\hline
\end{tabular}

\section{Calculation of Matric Potential}

The matric potential is the pressure potential that arises from the interaction of water with a solid matrix (Marshall and Holmes, 1992). In tuff, we assume that the suction potential is equal to the matric potential. Matric potential is defined by Kelvin's Law as

$$
\psi=\beta \mathrm{R} T \ln \left(e / e_{0}\right) / \mathrm{M},
$$

where $\psi$ is the matric potential in $\mathrm{MPa}, \beta$ is the density of water at the temperature of interest in $\mathrm{g} / \mathrm{cm}^{3}, \mathrm{R}$ is the universal gas constant $(8.314 \mathrm{~J} / \mathrm{Kmol}), T$ is temperature in $\mathrm{K}$, $e / e_{O}$ is the relative humidity, and $\mathrm{M}$ is the molecular weight of water $(18 \mathrm{~g} / \mathrm{mole})$. To determine the moisture retention curve, we placed the samples in a controlled humidity/ temperature environment. We monitored the sample weights and when they reached a constant value, we assumed equilibrium was established. A balance with a sensitivity of $0.01 \mathrm{mg}$, calibrated to a traceable standard, was used to weigh the samples. Saturation was calculated by comparing the constant value weights with dry weights, and adjusting for porosity.

Measurements began on dry samples. When a stable weight was achieved, the relative humidity $(\mathrm{RH})$ was increased and the process repeated at the same temperature. The maximum saturations achieved at the highest RH ( $\sim 98 \%)$ were approximately $25 \%$. After the measurements at the highest $\mathrm{RH}$ were complete, the samples were removed and saturated by immersing in water. The process was then repeated for the drying portion of the measurement. This cycle of measurement was then repeated at a different temperature. To minimize the effect of temperature on subsequent measurements, measurements were performed at room temperature on 12 samples 
of similar porosity. This group was then subdivided into several groups, each having similar moisture retention curves at $25^{\circ} \mathrm{C}$. One difficulty was the establishment of steady weight values at the highest humidities, particularly at $95^{\circ} \mathrm{C}$. RH is difficult to control at the highest settings, and the weight of the samples is more sensitive to changes in $\mathrm{RH}$ at the highest settings. Refining the measurement technique and setting control parameters on the humidity chambers helped stabilize weight values.

\section{Moisture Retention Results}

Moisture retention data at $25^{\circ} \mathrm{C}$ are complete. Figures 12(a) and (b) are plots of saturation as a function of matric potential at $25^{\circ} \mathrm{C}$ for wetting and drying. All the data points (from 12 samples) are plotted to demonstrate the heterogeneity of the material and hence the range of values obtained. The curve is plotted through the average of all 12 sample values. The dashed line shows the expected trend of the data at higher saturations as matric potential tends toward zero.

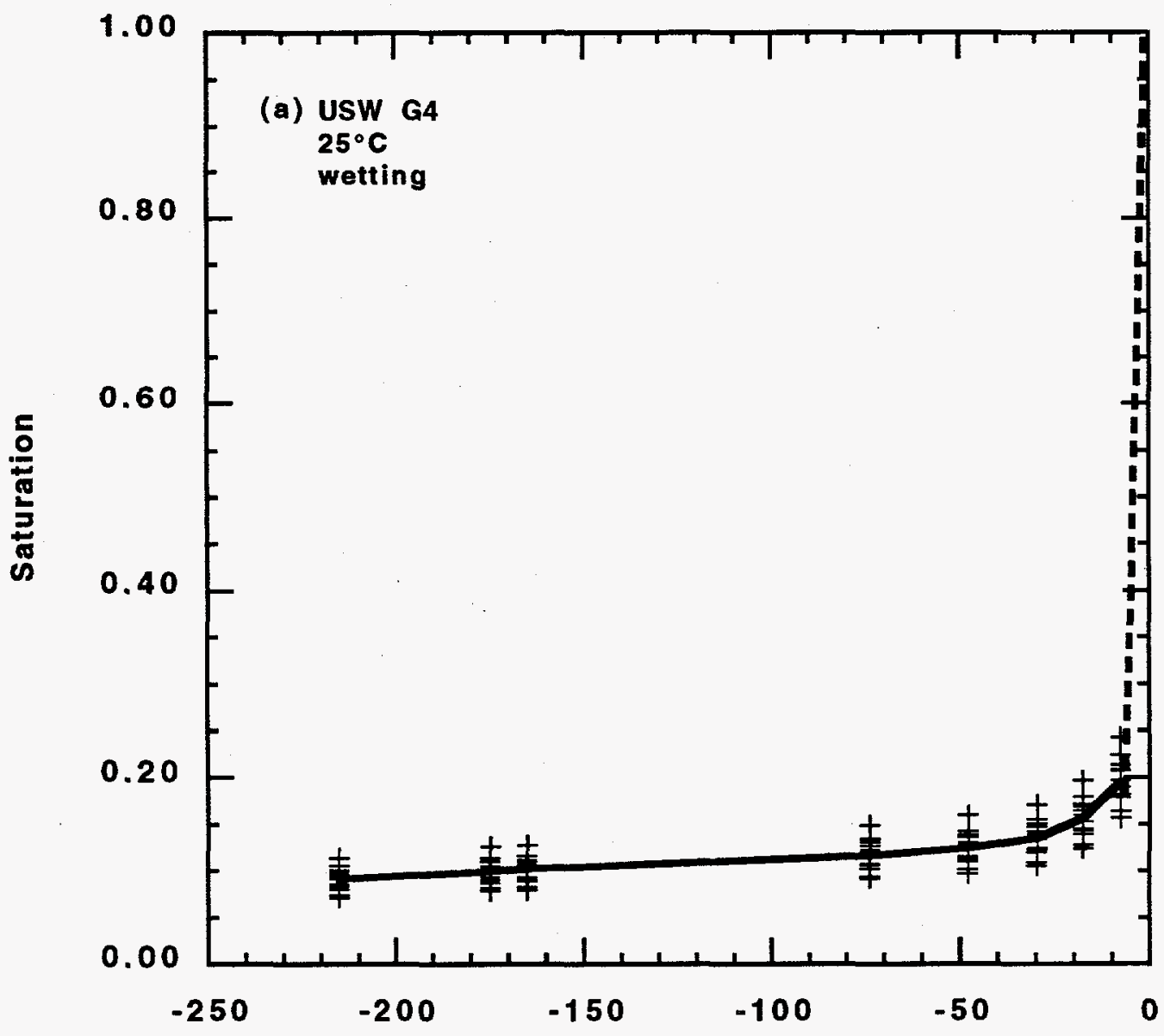

Matric Potential, MPa

Fig. 12. Saturation vs. matric potential (MPa) for 12 USW G4 samples at $25^{\circ} \mathrm{C}$ : (a) wetting curve. The dashed line indicates the expected trend. 




Matric Potential, MPa

Fig. 12. Saturation vs. matric potential (MPa) for 12 USW G4 samples at $25^{\circ} \mathrm{C}$ : (b) drying curve. The dashed line indicates the expected trend.

Figure 13 shows the data on an expanded saturation axis. The solid line is the average of 12 samples for wetting and the dashed line is the average for drying. Data from two individual samples are also shown, one above the average (circles), one below the average (squares). A small amount of hysteresis is observed.

Imbibition measurements at $95^{\circ} \mathrm{C}$ are complete and the drying portion is nearly finished. Figure 14 compares the data at $25^{\circ} \mathrm{C}$ with the wetting curve at $95^{\circ} \mathrm{C}$. The line through the $25^{\circ} \mathrm{C}$ data represents the average of 12 samples, and the line through the $95^{\circ} \mathrm{C}$ data represents the average of 3 samples. The matric potential is lower at higher temperature.

\section{Future Moisture Retention Measurements}

Moisture retention data will be taken at several temperatures between 25 and $95^{\circ} \mathrm{C}$. Measurements at temperatures greater than $95^{\circ} \mathrm{C}$ will also be conducted. An important part of this work will be the analysis of the effects of sample history (i.e., heating and cooling) on the moisture retention curves. 


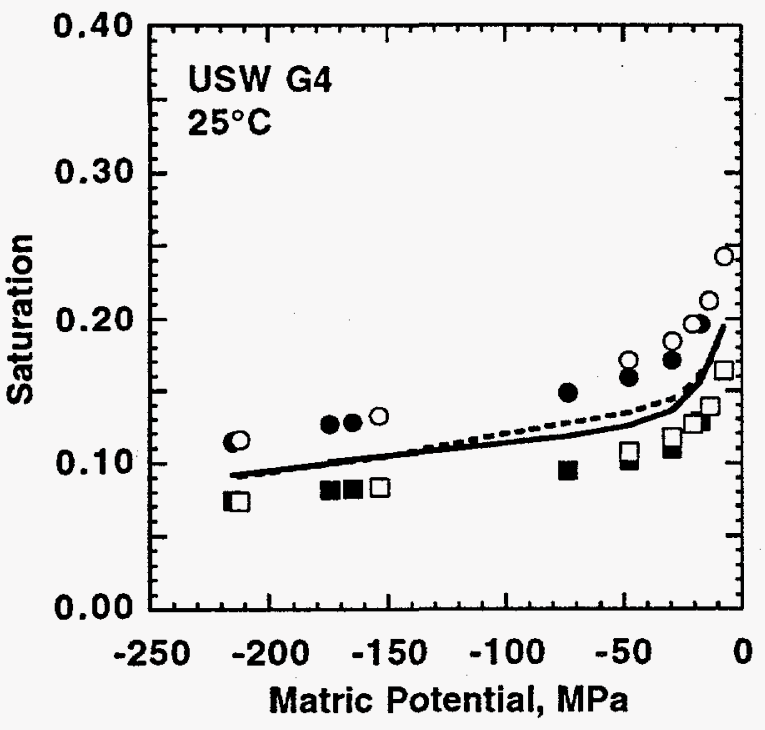

Fig. 13. Wetting and drying moisture retention curves at $25^{\circ} \mathrm{C}$ with expanded saturation axis. The solid line is the average for wetting and the dashed line is the average for drying (12 samples). Data from two individual samples are also shown, one above the average (circles) and one below (squares).

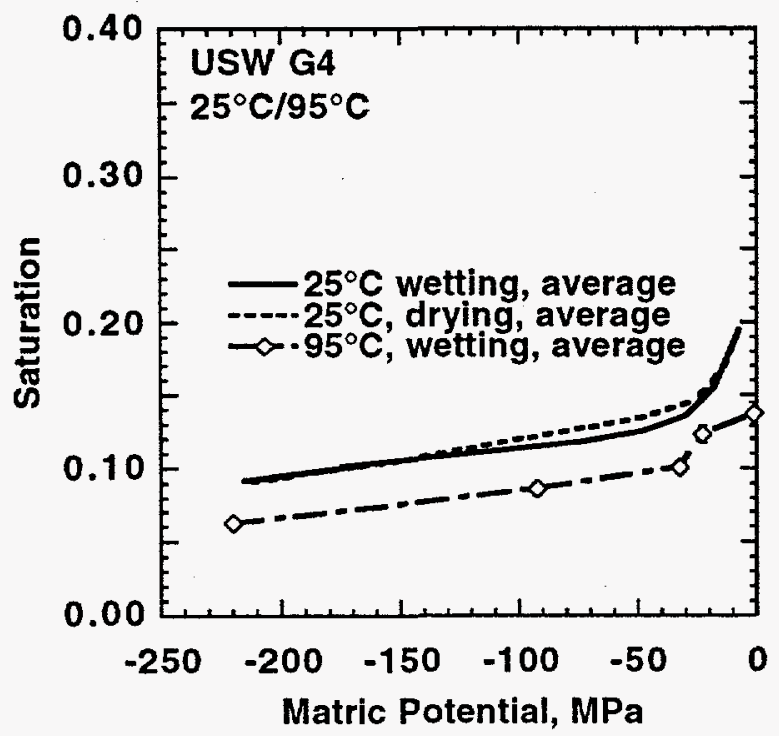

Fig. 14. Saturation vs. matric potential for 25 and $95^{\circ} \mathrm{C}$. The wetting curve at $95^{\circ} \mathrm{C}$ is lower than that at $25^{\circ} \mathrm{C}$.

\section{Acknowledgments}

Dave Ruddle and Ron Pletcher provided technical support and Kirk Keller assisted with the data collection system. The authors also acknowledge the helpful comments of Dwayne Chestnut. This work was supported by the Yucca Mountain Site Characterization Project.

\section{References}

Bevington, P. R., and D. K. Robinson, Data reduction and error analysis for the physical sciences, 2nd ed., McGraw-Hill, San Francisco, 328 pp., 1992. NNA.910523.001

Daily, W. D., W. Lin, and T. Buscheck, "Hydrological properties of Topopah Spring Tuff: Laboratory Measurements," J. Geophys. Res., 92, 7854-7864, 1987. NNA.900123.0064

Eisenberg, D., and W. Kauzmann, The structure and properties of water, Oxford Press, New York, 1969. MOL.19950314.0198

Lin, W., and W. D. Daily, Transport properties of Topopah Spring tuff, UCRL-53602, Lawrence Livermore National Laboratory, Livermore, CA, 1984. (Readily Available)

Lin, W., and W. D. Daily, "Laboratory study of fracture healing in Topopah Spring tuffImplications for near-field hydrology," Proceedings of the Topical Meeting on Nuclear Waste Isolation in the Unsaturated Zone, Focus '89, Las Vegas, NV, American Nuclear Society, 443-449, 1984. (Readily Available)

Marshall, T. J., and J. W. Holmes, Soil physics, 2nd ed., Cambridge Univ. Press, Cambridge, 374 pp., 1992. MOL.19950314.0199

Roberts, J. J., and W. Lin, Electrical Properties of Topopah Spring Tuff as a Function of Saturation, UCRL-JC-114784, Lawrence Livermore National Laboratory, Livermore, CA, 1994. (Readily Available) 


\title{
Appendix 1
}

\author{
ELECTRICAL PROPERTIES OF TOPOPAH SPRING TUFF \\ AS A FUNCTION OF SATURATION
}

\author{
Jeffery J. Roberts and Wunan Lin \\ Lawrence Livermore National Laboratory \\ PO Box 808, L-201 \\ Livermore, CA 94551 \\ (510) $422-7108$
}

\begin{abstract}
Estimates of water content in unsaturated regions based on electrical properties such as resistivity and dielectric permittivity depend on reliable laboratory measurements. We report measurements on three tuffs from Yucca Mountain, Nevada as a function of water saturation at $23^{\circ} \mathrm{C}$. Hysteresis is observed between the wetting and drying phases. Measurements made over a range of frequency verify measurements made at a single frequency and provide additional information about conduction mechanisms and microstructural parameters.
\end{abstract}

\section{INTRODUCTION}

Much attention has been focused on the hydrologic properties of tuff from the potential nuclear waste repository at Yucca Mountain, Nevada. The successful characterization of the near-field environment of the potential repository depends on the ability to understand and predict the movement of water within the matrix and fractures when the rock mass is heated by nuclear waste. This understanding will come only after many combined laboratory experiments, field tests, and model calculations have been performed. Electrical properties, including electrical resistivity and dielectric permittivity, have been utilized in past studies to infer water content in partially saturated rocks. In this study we determine the electrical properties of Topopah Spring tuff from Yucca Mountain (Area 25), and Area 3, Nevada Test Site (NTS), NV, as a function of water content. These results will be used to 1) study the electrical properties of partially saturated rocks as functions of saturation and water chemistry; 2) relate the observed electrical properties to the distribution of water and to the microgeometry of the rock; and 3 ) to create a database of electrical resistivity $(\rho)$ and relative dielectric permittivity $\left(\kappa^{\prime}\right)$ versus water content $(S w)$ and temperature for rocks within the potential repository horizon. The database will be used both in laboratory experiments and field tests to determine the moisture content in rocks based on measured electrical properties.

This report presents the measured electrical resistivity and dielectric permittivity as functions of water content at room temperature $\left(-23^{\circ} \mathrm{C}\right)$ of three tuffs from NTS. Both distilled water (DW) and J-13 well water (J-13) were used as pore fluids. Samples were prepared from cores obtained from boreholes USW GU-3 (GU3), $330 \mathrm{~m}$ depth (Area 25); USW G-4 (G4), $374 \mathrm{~m}$ depth (Area 25) and U3hg-1 (U3hg), $399 \mathrm{~m}$ depth (Area 3). The samples from GU3 and G4 are of particular importance because they are the same rock as at the potential repository horizon. The U3hg sample is included in the study to investigate the effect of porosity variation on the electrical properties.

\section{THEORETICAL BACKGROUND}

Impedance is the total opposition to current flow in response to an AC applied voltage. Impedance is a complex quantity, generally expressed as a magnitude and a phase $(\mathbb{Z l}, \phi)$, as a real component and an imaginary component $\left(Z^{\prime}, Z^{\prime \prime}\right)$, or as a resistance and a capacitance (R, C). In rocks impedance normally contains both resistive and capacitive components, and seldom contains an inductive component in the frequency range normally considered. The complex impedance $Z^{*}$ is given by

$$
\mathrm{Z}^{*}=\mathrm{Z}^{\prime}-\mathrm{j} \mathrm{Z}^{\prime \prime}
$$

where the asterisk denotes a complex quantity, a single prime indicates a real quantity, the double prime indicates an imaginary quantity, and $j$ is $\sqrt{ }-1$. The real and 
imaginary parts of the impedance are obtained from the measured quantities $\mid \mathrm{ZI}$ and $\phi$ determined at a given frequency by

$$
\begin{aligned}
& Z^{\prime}=|Z| \cos \phi, \\
& Z^{\prime \prime}=|Z| \sin \phi .
\end{aligned}
$$

The complex resistivity $\rho^{*}$ is obtained by multiplying the impedance by the geometric factor which is the area to thickness ratio of the sample, A/l. The complex conductivity $\psi^{*}$ is equal to the inverse of $\rho^{*}$. The complex conductivity is also represented as

$$
\psi^{*}=\sigma+\mathrm{j} \omega \varepsilon^{\prime},
$$

where the conductivity $\sigma=\omega \varepsilon ", \omega$ is the angular frequency, and $\varepsilon^{\prime}$ and $\varepsilon^{\prime \prime}$ are the real and imaginary parts of the dielectric permittivity. The complex dielectric constant $\varepsilon^{*}$ is related to the complex impedance through

$$
\varepsilon^{*}=\left(j \omega C_{0} Z^{*}\right)^{-1}
$$

where $C_{0}$ is the capacitance of the empty cell in vacuum $\left(C_{0}=\varepsilon_{0} A / /\right) . \varepsilon_{0}$ is the permittivity of free space and has a value of $8.854 \times 10^{-12} \mathrm{~F} / \mathrm{m}$. The complex relative permittivity can be written as

$$
\kappa^{*}=\kappa^{\prime}-j \kappa^{\prime \prime}=\left(j \omega C_{0} Z^{*}\right)^{-1} .
$$

$\kappa^{*}$ is the dielectric permittivity divided by the permittivity of free space, $\varepsilon_{0}$. The two other immittance functions are the complex admittance $\mathrm{Y}^{*}$ and modulus $\mathrm{M}^{*}$, however, these formalisms will not be used in this work.

The LCR meter is an auto balancing bridge that measures $|Z|, \phi, R$, and $C$. The $R$ value is determined by assuming a parallel RC circuit, the response of which is given by

$$
Z^{*}=\frac{R}{(\omega R C)^{2}+1}+\frac{j \omega C R^{2}}{(\omega R C)^{2}+1},
$$

Plotted in the complex impedance plane, the response of equation (7), and that of the rock, is represented by a semicircular arc that has its center fall approximately on the real axis (Figure 1). The $R$ value returned by the bridge is the value of the intersection of this arc with the real axis at the low frequency side, and is also the width of the arc. Complex impedance systems may have one or more conduction mechanisms represented by circuit elements that combine in various ways, i.e., in series or parallel. In this study it is observed that the electrode properties occur in series with the material properties. This can be verified by noting that in the complex impedance plane, two (or portions of two) impedance arcs separated in frequency are observed. The higher frequency portion corresponds to material properties. As noted previously, it was observed that the measured $R$ versus sample thickness, for samples of constant area, demonstrates that $\mathrm{R}$ is linearly dependent on sample thickness at frequencies as low as $1 \mathrm{kHz}$. The response at frequencies lower than this are assumed to contain electrode polarization phenomena. In real systems it is common for the impedance arc to have a center that falls below the real axis. 1,2 For the purpose of describing the general resistivity and dielectric properties of tuff as a function of $\mathrm{Sw}$, it is not necessary to consider these non-ideal situations. To understand more fully the electrical conduction processes at work in partially-saturated systems, it is necessary to consider non-linear electrical responses. A more in depth examination of the frequency dependent electrical response of the water/rock system is currently in progress.

\section{EXPERIMENTAL TECHNIQUES}

\section{A. Electrical Measurements}

The two-electrode technique was used to measure the complex impedance as a function of frequency using a four-terminal pair lead configuration. Data were taken with an HP 4274A LCR meter. The parameters measured for each sample at each saturation level were impedance magnitude, $|Z|$, phase angle, $\phi$, resistance, $R$, and capacitance, $C$. To ensure accurate measurements, the rock samples were machined into disks with a greater than 10:1 diameter to thickness ratio (to minimize possible surface conduction and fringing effects) and measurements were made over a range of frequency $\left(10^{2}-10^{5} \mathrm{~Hz}\right)$ enabling us to deduct contact impedance from the material properties. Electrical resistivity and relative dielectric constant were determined during both wetting and drying phases of a complete saturation/drainage cycle.

Additional measurements were made over a larger range of frequency $\left(10^{-2}-10^{5} \mathrm{~Hz}\right)$ using an EG\&G model 378 Electrochemical Impedance System. These supplemental measurements were used to investigate the frequency dispersion of the resistivity and dielectric permittivity in detail and to verify the measurements made using the HP 4274A. A comparison of measurements made using the two systems demonstrates nearly exact agreement. 


\section{B. Sample Descriptions and Sample Preparation}

Thus far we have studied three tuffs from the Nevada Test Site (NTS), Nevada. All the rocks are devitrified rhyolitic tuff composed primarily of quartz and alkali feldspar from the Topopah Spring member of the Paintbrush Tuff formation. The rocks are from cores obtained during drilling of boreholes. GU3 is densely welded, has a porosity of $9-10 \%$, and a dry bulk density of $2.35 \mathrm{~g} / \mathrm{cm}^{3}$. U3hg is welded, has a porosity of $25-28 \%$, and a dry bulk density of $1.86 \mathrm{~g} / \mathrm{cm}^{3}$. G4 is also densely welded, with a porosity of $9-14 \%$ and a dry bulk density of $2.34 \mathrm{~g} / \mathrm{cm}^{3}$. These and other microstructural parameters are summarized in Table 1.

To determine the dry density, the samples were dried in a vacuum oven at $35^{\circ} \mathrm{C}$ and weighed each day until the weights did not change for at least one day. The dry density is the ratio of dry weight and sample volume. The saturated weights were obtained by placing the dry rock in a vessel, evacuating it, and allowing distilled water to flood the sample. Once the water filled the vessel it was pressurized to $80 \mathrm{psi}$. The samples were considered saturated when the weights remained unchanged for at least one day. The porosity was determined by the difference in the saturated and dry densities, divided by the density of water. This procedure was performed for each individual sample. Additional sample parameters were determined by $\mathrm{Hg}$ porosimetry and $\mathrm{N}_{2}$ or $\mathrm{Kr}$ adsorption tests on material adjacent to the samples. These parameters are listed in Table 1.

The rock was machined into relatively thin, disk shaped samples with a diameter of $5.1 \mathrm{~cm}$. Four different samples of each rock were used in the measurements, each of a different thickness ( 2 to $5 \mathrm{~mm}$ thick). This permitted an evaluation of the homogeneity of the rock and allowed further determination of the effect of contact impedance. To reduce fringing and edge effects, the samples were prepared with a diameter to thickness ratio of $\geq 10$. The four different thicknesses were approximately $2,3,4$, and $5 \mathrm{~mm}$. The rocks were ground flat and parallel to within $0.025 \mathrm{~mm}$ using a 400 grit grinding wheel. The electrodes were sputtered Au approximately $100 \mathrm{~nm}$ thick on the circular surfaces of the disks, backed by gold foil $-50 \mu \mathrm{m}$ thick. The use of four samples provided a measure of rock heterogeneity, and by examining the impedance as a function of thickness, it could be determined if contact impedance affected the measurement. The impedance, or resistance, of an homogenous material should vary linearly with sample thickness. It was found that in the experiments of this study, over the frequency range $10^{3}-10^{5} \mathrm{~Hz}$, the electrodes had little or no effect on the impedance measurements.

The samples were machined in two different orientations: the disk surface parallel to the bedding and perpendicular to the bedding. The tuffs contain bedding planes that are perpendicular to the axes of the cores. Most of the samples were prepared such that the bedding planes are perpendicular to the axes of the cylindrical samples. Two samples from G4 were prepared with the bedding plane parallel to the cylindrical axis of the sample. The purpose of having the samples in two orientations is to evaluate the anisotropy of the electrical properties. Throughout the paper, the samples with the bedding plane parallel to the cylindrical axes are referred to as transverse samples and are designated by the letter $T$.

\section{Measurement Procedures}

Measurements began on initially dry samples and the saturation levels were gradually increased. Saturation levels were determined by

$$
S w=\frac{\text { weight }- \text { dry weight }}{\text { saturated weight }- \text { dry weight }}
$$

When DW was used as the pore fluid, the water saturation level was increased in three stages: 1) by moisture from the air, 2) by placing the samples in a humidity chamber between 20 and $98 \%$ relative humidity, and 3) by physically adding distilled water to the samples. Different levels of saturation were obtainable using each method depending on the sample characteristics. In general, a saturation ( $S w$ ) of $-2-4 \%$ was achieved using 1 ), $5-15 \%$ by method 2), and a maximum saturation of $85-99 \%$ was obtained by adding water to the samples (submersing the samples was necessary to obtain the highest saturation levels). During the wetting phase care was taken to allow sufficient time for water added to distribute evenly throughout the sample. One way in which this was achieved was to monitor the resistance of the samples as a function of time after water was added. It was observed that the resistance would decrease rapidly, reach a minimum then slowly increase to a final value. Since water was added to the edge of a sample at one point, it is assumed that the area near this point was nearly $100 \%$ saturated for a short period of time. This highly saturated zone provided a region of high electrical conductivity between the electrodes, effectively shorting out the sample. As time passed, the water distributed more evenly and the resistance reached the final value for that particular saturation level. The length of time required for this phenomenon to occur depended on several factors, 
including initial $\mathrm{Sw}$, amount of water added, and sample dimensions, but was generally less than one hour. A more careful analysis of this phenomenon may provide a means of determining unsaturated flow parameters. By monitoring the electrical properties as a function of time and introducing a known amount of water to a sample of known saturation state, it may be possible to determine the water distribution as a function of time. This will then enable the estimate of unsaturated permeability for a range of saturation.

Once the samples were completely saturated, they were placed in sealed sample holders. The drying phase began at this point. A measurement was made approximately daily during the drying phase. Immediately following a measurement, the samples were removed from the holders and weighed to determine Sw. Depending on the saturation level, the samples were allowed to dry slightly in the air before being put back in the sample holders. The lowest saturations during the drying phase were reached by drying the samples in an oven at $35-100^{\circ} \mathrm{C}$.

When $\mathrm{J}-13$ water was used as the pore fluid, the saturating procedure was similar to that described above except that the water was always physically added to the samples and the measurements were always performed with the samples in the sealed holders. This was done to prevent the dry samples from picking up moisture from the air that was different in composition than the J-13 water. It should be noted that the sealed holders were not $100 \%$ moisture proof. At high saturations $(>\sim 60 \%)$, there was a tendency for the samples to lose water as a function of time. This water loss was kept as low as possible through timing of the measurements. It is assumed that the small amount of evaporative loss did not change the electrical conductivity of the pore water or affect the measurement in any other adverse way.

\section{RESULTS AND DISCUSSION}

\section{A. Resistivity as a Function of Saturation}

Impedance magnitude and phase are plotted as a function of frequency for four levels of saturation of sample U3hg using DW as the saturating fluid in Figure 2a. This figure demonstrates clearly that dispersion affects both parameters. The impedance magnitude is less affected by frequency than phase angle. Only the lowest saturation (0.047) displays significant variation of $|Z|$ with frequency. The phase angle at each saturation displays significant variation with frequency. The level of saturation also has an effect on frequency dispersion of both impedance magnitude and phase angle, i.e., a less saturated sample displays a much higher level of dispersion. Dispersion diminishes with increasing saturation as evidenced by the same data plotted in the complex plane (Figure 2b). This diagram shows impedance arcs that shrink in size with increasing saturation. Over the frequency range plotted $\left(10^{2}-10^{5} \mathrm{~Hz}\right)$ very little of the electrode arc is observed, however, more of the electrode arc appears with increasing saturation. This indicates that the frequency range at which material properties are observed (as opposed to electrode properties) changes with saturation, and the direction of change is toward increasing frequency with increasing saturation. In general, resistance and resistivity measurements made at 1 $\mathrm{kHz}$ using a standard LCR meter are the most accurate over the entire range of saturation for the samples and sample sizes considered here. The above observations, while made for one specific tuff (U3hg), were found to be true for all the rocks of this study.

Resistivity versus saturation curves for all three rocks are shown in Figure 3. These measurements were made at a single frequency, $1 \mathrm{kHz}$. Only the curves using J-13 water are shown except for U3hg (b) which also has the DW curve. In spite of the very different resistivities of the saturating fluids $\left(39 \Omega \mathrm{m}\right.$ for $\mathrm{J}-13 ; 1.7 \times 10^{3} \Omega \mathrm{m}$ for $\mathrm{DW}$, measured at $25^{\circ} \mathrm{C}$ ) there is very little difference in the resistivity using the two pore waters except for sample U3hg. Possible explanations for this include: 1) U3hg has a much higher porosity than $\mathrm{G} 4$ and GU3, and because of this higher porosity the difference in the electrical conductivities of the pore waters is more important; 2) the higher surface area/pore volume ratios in G4 and GU3 quickly cause the DW to become chemically similar to J-13. This could also explain, in part, the large hysteresis observed between the wetting and drying phases for sample U3hg. All the samples display some degree of hysteretic behavior with the sample during the drying phase more resistive than during the wetting phase over the entire range of $\mathrm{Sw}$. This type of hysteretic behavior has been observed previously in partially saturated sandstones and our observations are consistent with those of that study. ${ }^{3}$

In general, all the rocks display a rapidly decreasing $\rho$ with increasing saturation that is nearly linear on a $\log \rho$ versus Sw plot. Sample U3hg displays the steepest decrease, followed by GU3 and G4. This is also the order of porosity, from highest to lowest. With increasing saturation, above 0.1 to $0.2 \mathrm{Sw}$, the resistivity decreases more gradually to a final value at $1.0 \mathrm{Sw}$. We attribute the differences in the observed resistivity versus saturation curves for the different rock types to differences in the microgeometry of the rocks. 
Sample U3hg (b) displays unusual behavior, that is, there is a substantial increase in resistivity with increasing saturation using DW above $0.7 \mathrm{Sw}$. The increase in $\rho$ above $0.7 \mathrm{Sw}$ is not observed in the drainage cycle (i.e., $\rho$ does not decrease in going from 1 to $\sim 0.7 \mathrm{Sw}$ ). The lowest resistivity of the DW wetting curve for U3hg occurs at $\sim 0.68 \mathrm{Sw}$, and is below the resistivity of the saturating fluid. This indicates that 1) some mechanism is at work within the water-rock system that is more conductive than either the fluid or the rock, or 2) the DW quickly becomes more conductive by the addition of conductive species through the dissolution of minerals in the rock sample or salts on the surface of pores within the rock. The resistivity measurements on U3hg using J-13 water show similar behavior, again hysteresis is observed and the rock is less resistive during the wetting phase than during the drying phase. Samples G4 and GU3 display a slight increase in resistivity with increasing saturation above $-0.85 \mathrm{Sw}$ during the wetting cycle only.

The phenomenon of increasing resistivity with increasing saturation during wetting of sandstone has been observed and previously reported by Knight, 1991.' She used DW as the saturating fluid and found the process to be repeatable up to a point, that is, upon drying a sample completely, re-saturating it produced similar $\rho$ versus $S w$ curves that contained a jump in resistivity at some specific saturation. However, this jump was not always observed. The proposed explanation for this behavior is the surface of the water near the water-air interface provides a relatively conductive pathway when continuous. The increase in resistivity is observed when enough water is added to the sample that the water-air interface is no longer continuous throughout the sample and the electrical pathway is broken. It is not known why this process occurs only part of the time. Further investigation of this behavior in tuff rocks from Yucca Mountain is currently underway. Through the use of impedance measurements conducted over a large range of frequency, we are obtaining information related to the nature of conduction at the rock-water, and water-air interfaces.

Figure 3d shows a comparison of the electrical resistivity of G4 with respect to direction of measurement. The transverse samples (bedding planes in the direction of measured electrical resistivity) are slightly less resistive than the samples with bedding planes perpendicular to the direction of measured electrical resistivity. A likely explanation for the decreased resistivity as measured in the transverse direction is the preferred alignment of the high aspect ratio pores (elongated) in the direction of bedding. The difference in resistivity is small and most likely will not affect the use of electrical resistivity measurements for the determination of $\mathrm{Sw}$ in other laboratory and field tests.

Archie's law has commonly been used to describe electrical properties as a function of saturation (e.g., Collins, 1961). ${ }^{4}$ This empirical relationship,

$$
\rho=\rho_{\mathrm{o}} S w^{-n},
$$

relates the resistivity at saturation $S w(\rho)$ to resistivity at $S w=1.0\left(\rho_{0}\right)$ times saturation $(S w)$ to the exponent $n$. The ratio $\rho / \rho_{O}$ is referred to as the resistivity ratio. For the rocks of this study, Archie's law fails to describe the resistivity over the entire range of saturation. In particular, Archie's law fails at the very lowest saturations $(S w<\sim 0.2)$ for both wetting and drying phases and the high saturations ( 0.7-1.0) during the wetting phase when an increase with resistivity with increasing saturation occurs.

Other attempts to model the resistivity over the entire range of saturation have met with varied success. The drying curves of most samples studied can be modeled using a parallel conduction model,

$$
\rho(S w)=\left\{S w / \rho_{1}+(1-S w) / \rho_{2}\right)^{-1},
$$

where $\rho_{1}$ and $\rho_{2}$ are two separate conduction (resistivity) mechanisms that add in a parallel manner. The advantage of this approach is that it is a simple mixing model and physically realistic. Additional support for this model comes from the complex impedance diagrams where only one impedance arc is observed that relates to material properties. In other studies a single impedance arc is often taken as evidence for parallel type conduction behavior, ${ }^{5}$ although additional complications can be added to the models. One such complication introduced to the parallel model is a surface conduction in the form of a cation exchange capacity (CEC) by Waxman and Smits. ${ }^{6}$ This model has met with considerable success, particularly when clays are present in the rock matrix. The CEC of tuff from Yucca Mountain has been measured and in tuffs similar to those of this study was found to be quite small $(3.1 \mathrm{meq} / 100 \mathrm{~g}) .^{7}$ This is consistent with the very low clay content found in the tuffs.

Alternative models are currently being studied and developed. It is hoped that continued study will provide more understanding as to the physical mechanisms of electrical conduction in the partially saturated rock, including the cause of the increase in $\rho$ at high Sw during the wetting phase. 


\section{B. Dielectric Properties}

Figure 4 shows the real relative permittivity for all the tuffs as a function of $\mathrm{Sw}$ for both wetting and drying, measured at $100 \mathrm{kHz}$. Only the results using J-13 water as the saturating fluid are shown. Similar to the case of $\rho$ versus Sw, hysteresis is observed, except in sample U3hg. It is interesting to note that U3hg displays the largest hysteresis of electrical resistivity, but the lowest hysteresis of dielectric permittivity. The measured ${ }^{\prime}$ ' during the drying phase is lower than $K^{\prime}$ during the wetting phase. For all the dry samples the $\kappa^{\prime}$ value is $\sim 5$. There is a significant difference in $\kappa^{\prime}$ of the saturated samples. At saturated conditions, $\boldsymbol{k}^{\prime}$ for U3hg is about 61, while GU3 and G4 have values of approximately 42 . The value of $\boldsymbol{\kappa}^{\prime}$ for pure water is approximately 78 at room temperature. ${ }^{8}$ This value is not reached at any point along the Sw curve. While GU3 and G4 have similar saturated permittivities, the shapes of the $\kappa^{\prime}$ vs. Sw curves are quite different. These differences are again attributed to differences in microstructure. Similar to the case of $\rho$ vs. $\mathrm{Sw}$, the $\mathrm{K}^{\prime}$ vs. Sw plots for G4 and G4-T display no significant anisotropy in $\kappa^{\prime}$.

As shown in Fig. 3, $\rho$ becomes relatively insensitive to $S w$ for saturations between 0.6 and 1.0. However, $\kappa^{\prime}$ seems to be a strong function of $S w$ even at high saturations. This indicates that dielectric permittivity may be a better parameter than electrical resistivity for use in determining saturation. We currently have not modeled ${ }^{\prime}$ as a function of saturation. Previous work on sandstones has shown success by using the complex refractive index method (CRIM). ${ }^{8,9}$ Future work includes a modeling effort using the CRIM method.

\section{CONCLUSIONS}

We have generated a useful database for inferring moisture content based on electrical properties. We have shown that the electrical resistivity and dielectric permittivity of Topopah Spring Tuff show a strong dependence on water saturation at low saturation levels and become less sensitive to $S w$ as $S w$ increases. At high $S w$, dielectric permittivity is more sensitive to $S w$ than is electrical resistivity. The difference in the electrical resistivities when using DW and J-13 water is small except for the more porous tuff (U3hg-1). Hysteresis between the wetting and drying phases of a complete saturation drainage cycle is observed in measurements of both resistivity and dielectric permittivity. Measurements on samples as a function of direction show little anisotropy in either electrical resistivity or dielectric permittivity. The different electrical characteristics of the three rocks are due mainly to differences in porosity and pore size distribution. For GU3 and G4 these differences are very small. Studies to understand these correlations are currently underway.

\section{ACKNOWLEDGMENTS}

Dave Ruddle provided technical support and Kirk Keller assisted with the data collection system. This work was supported by the Yucca Mountain Site Characterization Project. Work performed under the auspices of the US. Department of Energy by Lawrence Livermore National Laboratory under contract W-7405-ENG-48.

\section{NOMENCLATURE}

$\begin{array}{ll}\text { A } & \text { sample area } \\ \mathrm{C} & \text { capacitance } \\ \mathrm{I} & \text { sample thickness } \\ \mathrm{M}^{*} & \text { complex modulus } \\ \mathrm{R} & \text { resistance } \\ \mathrm{S} w & \text { saturation } \\ \mathrm{Y}^{*} & \text { complex admittance } \\ \mathrm{Z}^{*} & \text { complex impedance } \\ |\mathrm{Z}| & \text { impedance magnitude } \\ \mathrm{Z}^{\prime} & \text { real impedance } \\ \mathrm{Z}^{\prime \prime} & \text { imaginary impedance } \\ \sigma & \text { electrical conductivity } \\ \varepsilon^{*} & \text { complex dielectric permittivity } \\ \kappa^{*} & \text { complex relative permittivity } \\ \kappa^{\prime} & \text { real relative permittivity } \\ \phi & \text { phase angle } \\ \rho & \text { resistivity } \\ \psi^{*} & \text { complex conductivity } \\ \omega & \text { angular frequency }\end{array}$

\section{REFERENCES}

1. A. K. Jonscher, "The interpretation of non-ideal dielectric admittance and impedance diagrams," Phys. Status. Solidi, 32, 665-676, (1975).

2. R. L. Hurt and J. R. Macdonald, "Distributed circuit elements in impedance spectroscopy: A unified treatment of conductive and dielectric systems," Solid State Ionics, 20, 111-124, (1986).

3. R. Knight, "Hysteresis in the electrical resistivity of partially saturated sandstones," Geophysics, 56, 2139-2147 (1991). 
4. R. Collins, "Flow of fluids through porous materials," ch. 2, Reinhold Publishing Corporation, New York, (1961).

5. N. Bonanos, B. C. H. Steele, and E. P. Butler, "Characterization of materials," in Impedance Spectroscopy, J. R. MacDonald, ed., pp. 191-237, Wiley \& Sons, N.Y., N.Y., (1987).

6. M. H. Waxman and L. J. M. Smits, "Electrical conductivities in oil-bearing shaly sands," Soc. Pet. Eng. J. Trans., AIME, 243, 107-222, (1968).

7. K. W. Thomas, "Summary of sorption performed with Yucca Mountain, Nevada tuff samples and water from well J-13," Los Alamos National Laboratory Report LA-10960-MS, (1987).
8. P. H. Nelson, "Estimation of water-filled and air-filled porosity in the unsaturated zone, Yucca Mountain, Nevada, "High Level Radioactive Waste Management, Proc. Fourth Annual Int. Conf., Las Vegas, Nevada, April 26-30, 1993, 949-954, American Nuclear Society, La Grange Park, Illinois, (1993).

9. R. Knight and A. Endres, "A new concept in modeling the dielectric response of sandstones: Defining a wetted rock and bulk water system," Geophysics, 55, 586-594, (1990). 
FIGURES

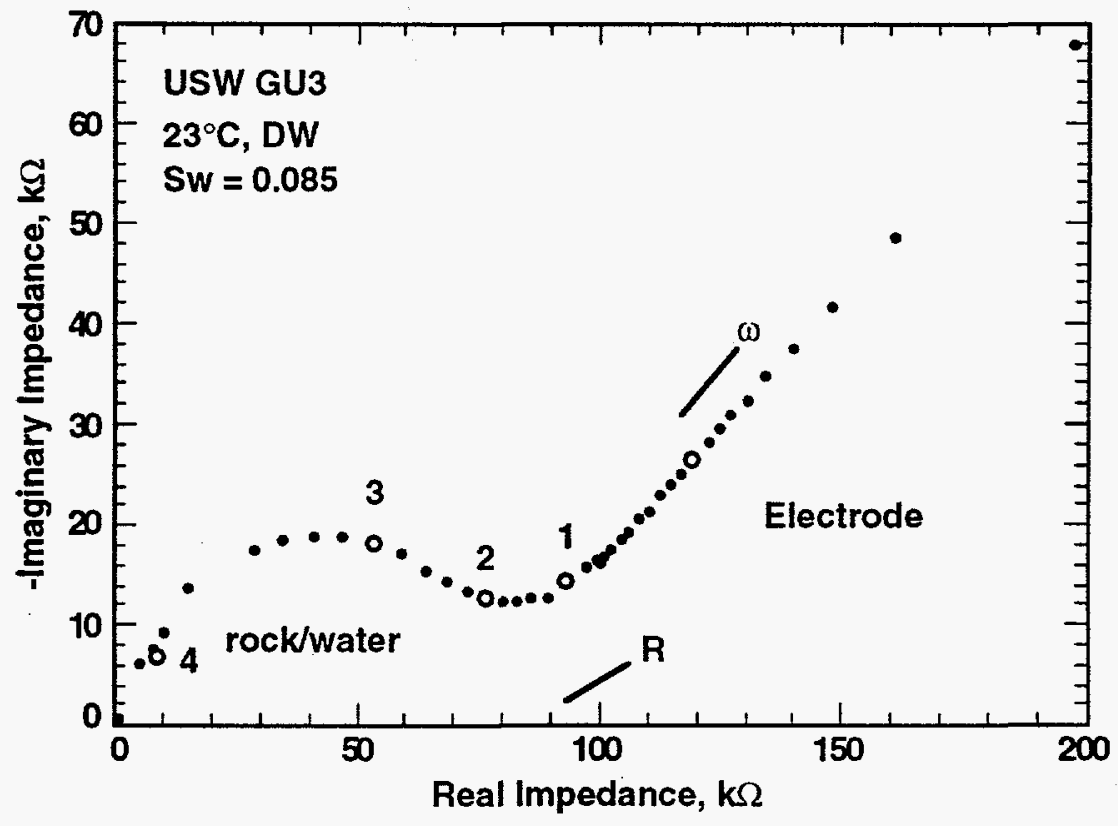

Fig. 1. Complex impedance diagram of -imaginary impedance versus real impedance for sample USW GU3 using DW as the saturating fluid at a saturation of 0.085 . Frequency increases toward the origin. An open circle is plotted at each decade of frequency, the numerals represent $\log 10$ of the frequency (in $\mathrm{Hz}$ ) of the corresponding point. Portions of two impedance arcs are observed. At high frequency the response corresponding to conduction through the rock/water system is observed, at lower frequencies the electrode response is observed. $R$ indicates that point where the high frequency arc intersects the real axis, this is the width of the impedance arc and hence, the resistance value. 

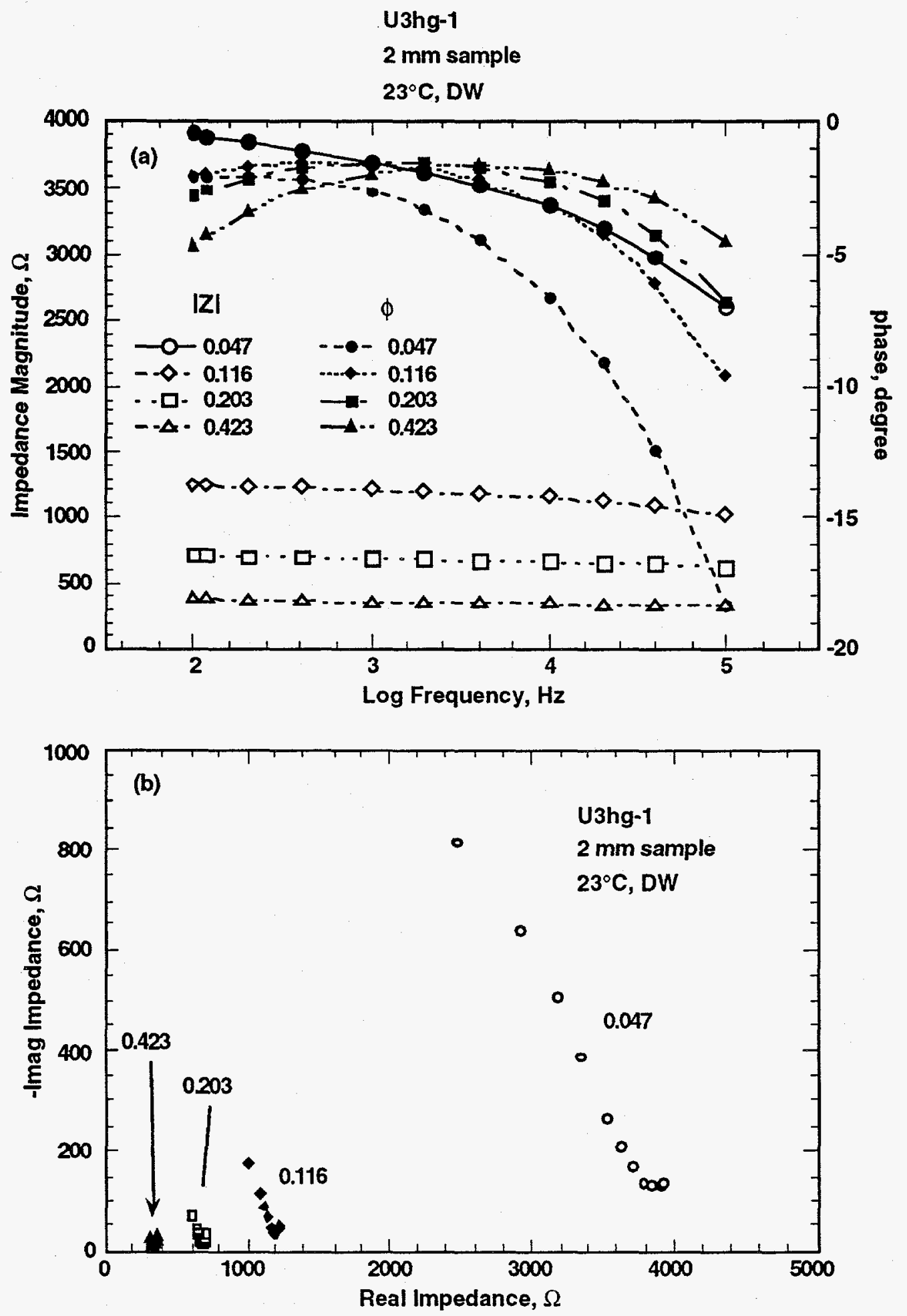

Fig. 2. (a) Impedance magnitude and phase angle as a function of log frequency for U3hg-1 (2 mm thick sample) at $23^{\circ} \mathrm{C}$ using DW as the saturation fluid. Open symbols correspond to impedance magnitude, filled symbols correspond to phase angle. Four saturations are shown; circles-0.047, diamonds- 0.116 , squares -0.203 , triangles- 0.423 . Both the impedance magnitude and the phase angle display dispersive behavior. Dispersion is greater for dryer samples. (b) The same data as (a) plotted in the complex impedance plane. 

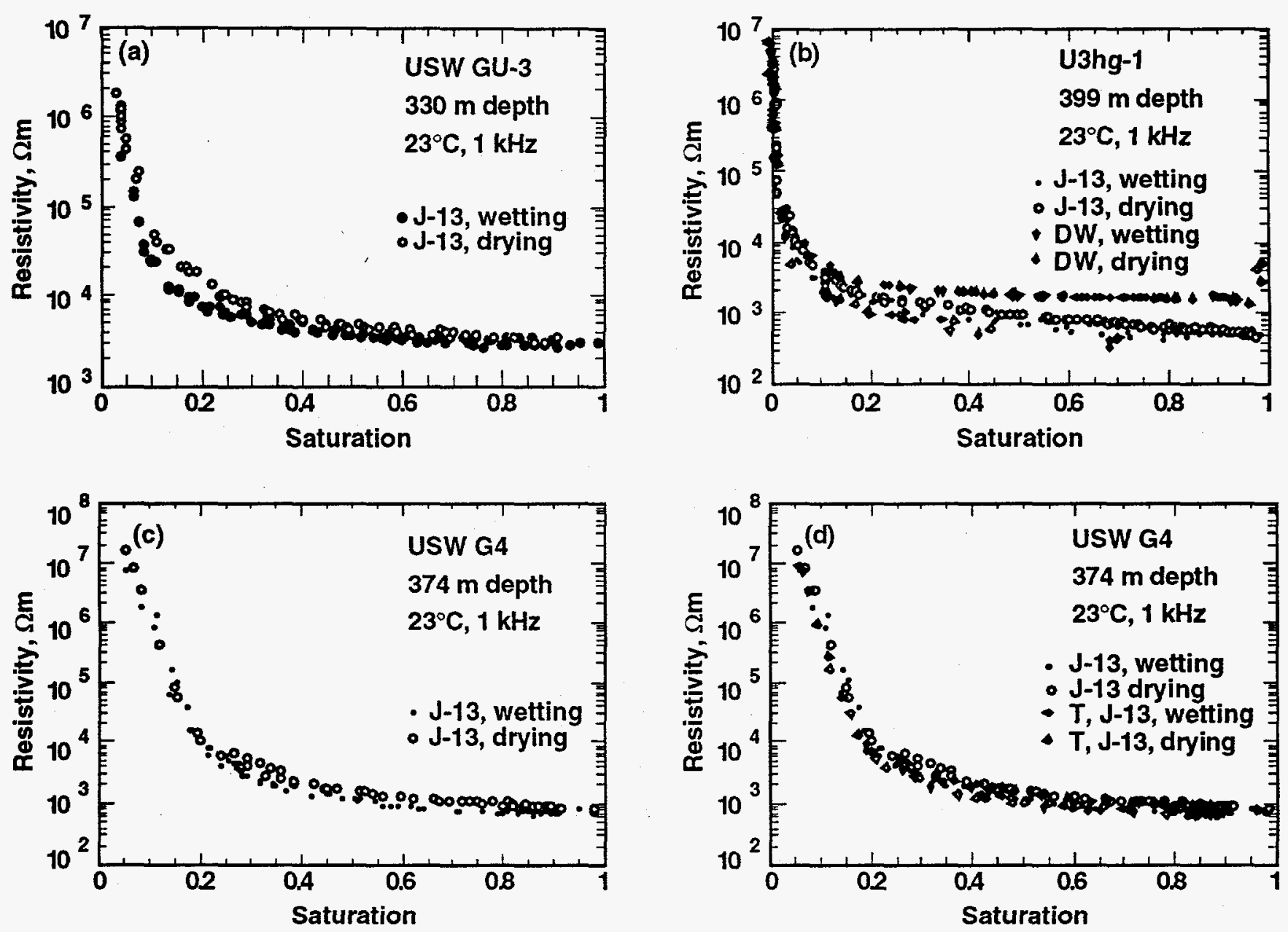

Fig. 3. Resistivity $(\Omega \mathrm{m})$ as a function of saturation measured at $1 \mathrm{kHz}$. Filled circles represent the wetting phase, open circles the drying phase. J-13 is the saturating fluid except where noted. (a) USW GU3, (b) U3hg-1, J-13 (circles) and DW (diamonds), (c) USW G4, (d) USW G4 measurements made perpendicular (circles) and parallel (transverse, diamonds) to the bedding direction. 

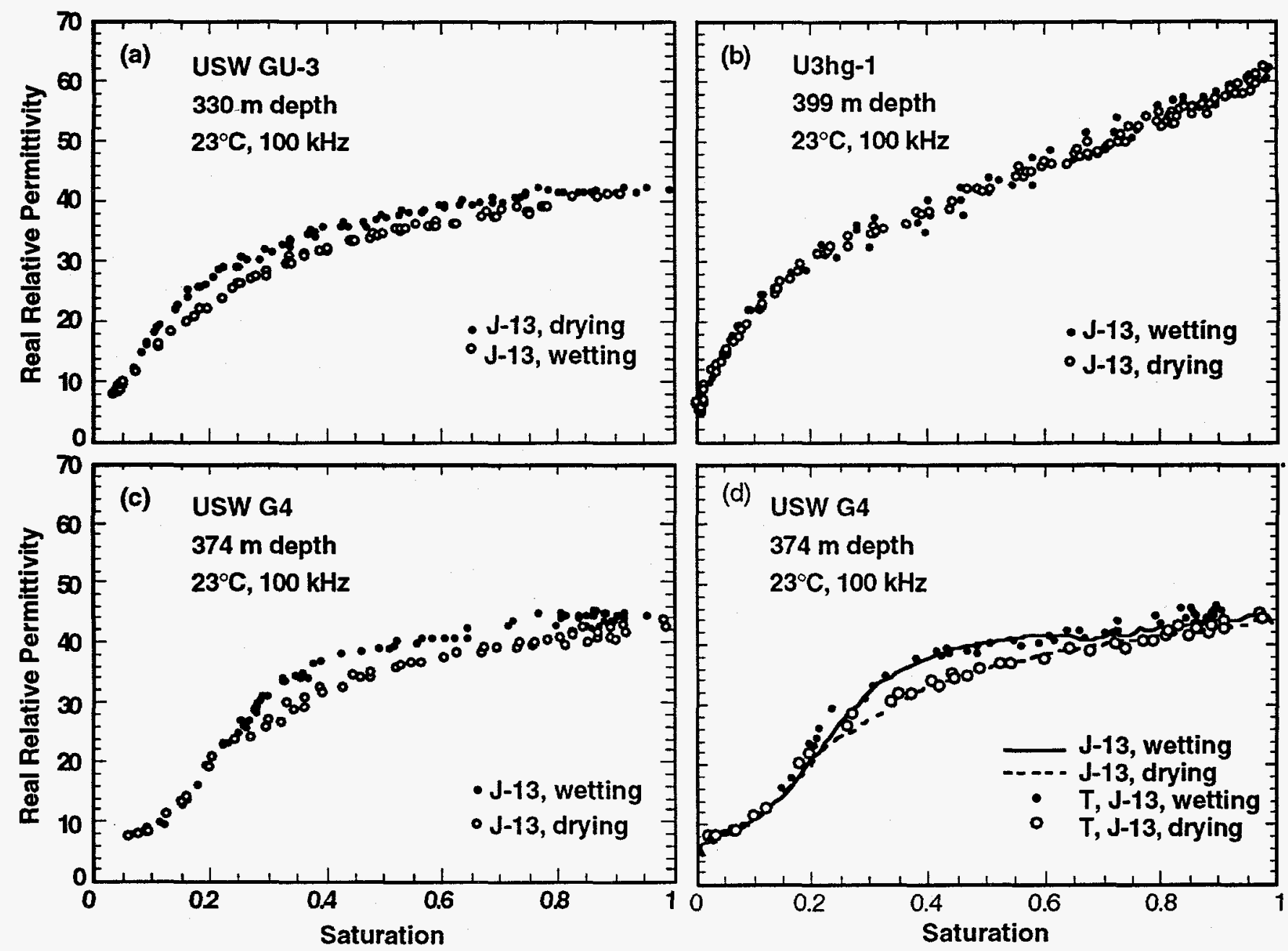

Fig. 4. Real relative permittivity as a function of saturation measured at $100 \mathrm{kHz}$ using J-13 as the saturating fluid. Filled circles represent the wetting phase, open circles the drying phase. (a) USW GU3, (b) U3hg-1, (c) USW G4, (d) USW G4, measurements made perpendicular (circles) and parallel (transverse, diamonds) to the bedding direction. 
Table 1. Materials studied.

\begin{tabular}{|c|c|c|c|}
\hline & $\begin{array}{c}\text { U3hg-1 } \\
\text { Topopah Spring } \\
\text { Tuff Area } 3\end{array}$ & $\begin{array}{c}\text { USW G4 } \\
\text { Topopah Spring } \\
\text { Tuff } \\
\end{array}$ & $\begin{array}{c}\text { USW GU3 } \\
\text { Topopah Spring } \\
\text { Tuff } \\
\end{array}$ \\
\hline Description & welded tuff & densely welded tuff & densely welded tuff \\
\hline Depth, $m$ & 399 & 374 & 330 \\
\hline Porosity & $25-28 \%$ & $9-14 \%$ & $9-10 \%$ \\
\hline Dry bulk density, $\mathrm{g} / \mathrm{cm}^{3}$ & 1.86 & 2.34 & 2.35 \\
\hline Skeletal density, $\mathrm{g} / \mathrm{cm}^{3}$ & 2.53 & 2.57 & 2.58 \\
\hline Surface area, $\mathrm{m}^{2} / \mathrm{g}(\mathrm{BET})$ & 2.946 & 1.769 & 1.399 \\
\hline Average pore diameter $\AA$ (BET) & 99 & $\mathrm{nd}$ & $\mathrm{nd}$ \\
\hline Surface area/volume, $\mathrm{cm}^{-1}$ & 14334 & 11703 & 11534 \\
\hline Average pore diameter, $\AA$ ( $\mathrm{Hg})$ & 531 & 214 & 197 \\
\hline
\end{tabular}
nd- not determined 